\title{
Political Participation, Regional Policy and the Location of Industry
}

\author{
Magnus Wiberg*
}

April 14, 2010

\begin{abstract}
This paper analyzes the location of manufacturing activities when regional policy is determined by each region's relative propensity to vote. Once voting over government transfers to regions is included in an economic geography framework with size asymmetries, the standard prediction that the larger region becomes the core when trade barriers are reduced no longer holds. The establishment of manufacturing production in the economically smaller region is increasing in the level of regional integration. As trade is increasingly liberalized, the economy eventually features a reversed core-periphery equilibrium where all firms reside in the South. It is further shown that the relative political participation rate increases in the factor scarce region as trade is liberalized. Empirical evidence shows that the model is consistent with qualitative features of the data.
\end{abstract}

Keywords: Economic Geography; Regional Policy; Voter Turnout

JEL Classification: D72; F12; R12

*This paper was written when the author was visiting the Department of Economics, Harvard University, Littauer Center, 1805 Cambridge Street, Cambridge, MA 02138. Current affiliation: Swedish Government Offices. SE-103 33 Stockholm, Sweden. E-mail: magnus.wiberg@finance.ministry.se. Phone: 0046737271224. 


\section{Introduction and Related Literature}

As is well known, the basic models of the New Economic Geography predict that in some circumstances, smaller peripheral economies can be deindustrialized due to economic integration. In contrast, this paper argues that smaller regions have a relatively higher rate of political participation, which enables them to capture relatively larger rents in a voting contest for firm subsidies. It is shown that this can reverse the agglomeration process implied by standard geography models.

Theories of voter participation explain that certain groups are ignored by the political system because they do not or cannot participate in politics. Citizens have the votes that politicians need, and elected officials have incentives to reward high voting groups to win elections. Empirical studies have found a relationship between political participation and political rewards at the state, local, and federal level. For example, at the U.S. state level, spending on welfare benefits is related to the level of turnout by the poor, and welfare spending is significantly higher in states where the poor vote at higher rates (Hill and Leighley, 1992). At the local level, public services improved for blacks when they entered the electorate more fully after the Voting Rights Act of 1965 (Button, 1989; Keech, 1968). At the federal level, Strömberg (2004) shows that U.S. counties with a high voter turnout were significantly more successful in attracting New Deal relief spending. Moreover, Martin (2003) confirms that members of the Congress direct federal resources to geographic areas within congressional districts that vote at higher rates; and Hicks and Swank (1992) find a positive relationship between turnout and welfare spending in advanced industrial nations. Also Horiuchi and Saito (2007) show that Japanese municipalities with a higher voter turnout receive significantly more regional subsidies. In sum, voters that participate in elections at higher levels, and geographic regions with a high turnout, are relatively privileged and more likely to be represented in the policy-making process at all levels of government.

Many countries devote a large part of their national budget to regional policies. These policies are designed to support the development of backward regions substantially below the average of other regions. However, according to Homburg (1997), GNP per capita had no effect on net transfers within the European Union in 1992, while population size was significantly negatively related to the allocation of regional funds. Robert-Nicoud and Sbergami (2004) explain this by arguing that the population in smaller regions is more 
politically homogenous. Therefore, politicians will find that a given subsidy level can buy more votes when the subsidies are distributed to firms based in these areas, where there are relatively more swing voters. Their approach suffers from two problems.

First, their result is derived by assuming asymmetric regional ideological preferences: the social and economic activities are more heterogeneous in the larger region, which makes the office-motivated political candidates by design adjust their policy platform to the economic interest of the electorate in the smaller region. The urban and larger region is according to this view characterized by a relatively higher level of ideological heterogeneity. However, this crucial assumption is not supported by data. Campbell (2006) shows that ideological heterogeneity is not determined by the percentage of a community's population that is urban. Among the most politically homogenous communities in the U.S. are St. Paul, the capital and second most populous city in Minnesota, and Rochester, the third largest city of New York, and metropolitan Detroit. Among the most heterogenous is the small city of Boulder in Colorado. Interspersed is also the state of Montana, which is predominantly rural (Campbell, 2006).

Second, an empirical test of their model is not straightforward. The number of swing voters is a latent variable, cannot be observed, and must be inferred by some indirect estimation method. The validity of this procedure rests on a number of specific assumptions of the distribution of ideological preferences among voters; for example, that preferences are symmetric and single peaked.

The current paper provides a complementary explanation for the location of firm activity by letting regional policy be determined by a voting process (Feddersen and Sandroni, 2006), where so-called ethical agents participate when they are morally obligated to do so. This solves for the distribution of industry as a function of an observable political variable: the regional voter turnout level. The model therefore provides a framework that readily can be applied to empirical analysis. ${ }^{1}$

\footnotetext{
${ }^{1}$ In the present framework, government transfers are solely determined by the relative regional political participation rate. Regional policy can, naturally, be motivated by special interest pressure. (See for example Wiberg [2010] for a lobbying-based approach to analyze how regional policy affects the location of industry.) Although Cadot et al. (2006) argue that electoral concerns is a more direct determinant than lobbying for subsidies, the voter turnout mechanism applied in this paper should be seen as complementary to, rather than an argument in favor of, an interest group explanation.
} 
The economic setting, with asymmetric-sized regions, where capital is inter-regionally mobile, gives rise to the home market effect (Krugman, 1980). That is, as trade barriers are gradually lowered, the allocation of industry shifts towards the larger region (the North). Further liberalization continues to benefit the larger region until all industry agglomerates in the North. When regional policy is determined by each region's relative propensity to vote, this standard prediction no longer holds. Applying the duty-based voting model of Feddersen and Sandroni (2006), it is shown that the equilibrium location of industry in the economically smaller region (the South) is increasing in the level of economic integration. The reason is that voters in the South, due to a relatively lower social cost of increasing the political participation rate, reward policy with a relatively higher turnout compared to voters in the North. The political equilibrium therefore involves net subsidization of manufacturing production in the South. As trade is increasingly liberalized, the economy eventually features a reversed core-periphery equilibrium where all firms reside in the South.

These findings qualitatively resemble those of Robert-Nicoud and Sbergami (2004), where the smaller region can attract more than a proportional number of firms, if it has a sufficiently large number of swing voters. However, as already noted, their result is obtained by assuming asymmetric regional ideological preferences, such that the office-motivated political candidates design their policy platforms to the economic interest of the electorate in the South. Furthermore, their reversed core-periphery equilibrium is not subgame perfect in the sense that firms internalize the subsidy-included return to capital when relocation decisions are made. In their model, given that all economic activity is agglomerated in the South, subgame perfection means that any firm could have increased its subsidy-included rate of return by relocating to the North, since the reversed location equilibrium implies that the relative return to capital must be higher in the North. In contrast, in the current paper, and by the structure of the location game considered, the production shifts towards the relatively smaller region until all the gains from subsidies are exhausted. Since the smaller region is subsidized for all trade costs, and regional policy becomes relatively more efficient in attracting industrial activity when trade is liberalized, firms can increase their subsidy-included return to capital by shifting production to the South until this region obtains the entire manufacturing industry.

It further follows from combining the voting and geography model that the relative political participation rate increases in factor scarce regions as 
trade is liberalized. In other words, it is shown that globalization increases the political activism in poorer regions.

Empirical evidence on Swedish county-level data supports the view that voter turnout is a significant determinant of the location of industry. The empirical framework also confirms the prediction of Robert-Nicoud and Sbergami (2004), that firms locate to politically homogenous regions. The use of a Swedish data set offers some attractive features to identify a turnout effect via the allocation of firm subsidies on location outcomes. First, Swedish counties are homogenous with respect to the distribution procedure of regional funds. Second, subsidies are distributed by the Swedish government, government agencies, and the government's regional representatives on an application basis. The set-up of this decision-making mechanism gives reason to believe that, besides equity and efficiency concerns, re-election considerations of the sitting government may be a factor in the distribution of grants across counties. Thus, regional political participation could potentially affect the allocation of firm subsidies and, as a result, the location decisions of firms. Arguably, the empirical result that firms locate at higher rates to regions with higher turnout may generalize to countries with similar distribution procedures.

The rest of this paper is organized as follows. The next section presents the economic geography framework, and solves for the equilibrium location of industry when the regional policy variable is taken as exogenous. Section 3 sets out the voting framework that decides the size and direction of the policy instrument. In Section 4, the political model is integrated into the economic model and the two are solved together. Section 5 discusses the empirical strategy, the data set and variable definitions, and then tests some of the theoretical implications of the model. Section 6 concludes, and all proofs are in the Appendix.

\section{The Economic Model}

The economic model uses the Martin and Rogers (1995) framework, which is based on the Flam-Helpman (1987) version of the Dixit-Stiglitz (1977) model of monopolistic competition. 


\section{$2.1 \quad$ Assumptions}

There are two regions, two sectors and two factors. Specifically, the two regions, North $(N)$ and South $(S)$, belong to the same country and are endowed with two factors, labor $(L)$ and capital $(K)$. The regions are symmetric in terms of tastes, technology, openness to trade, but differ in their factor endowments; the North is a scaled-up version of the South. Thus, the regions may be of different size, but they have identical capital-labor ratios. In particular, the North's endowment of both capital and labor is $\lambda>1$ times the South's endowment. For this reason, $\lambda$ can be interpreted as the relative economic strength of the North.

The two sectors are referred to as agriculture $(A)$ and manufacturing, or industry $(M)$. The agricultural sector is assumed to produce a homogenous good under constant returns to scale and perfect competition using $a_{A}$ units of labor per unit of output. Labor is the only input and this good is chosen as a numeraire. The manufacturing sector uses both labor and capital to produce a differentiated good under increasing returns to scale and monopolistic competition. Following Flam and Helpman (1987), the production of each differentiated good involves a one-time fixed cost consisting of one unit of $K$, and a per-unit-of-output cost of $a_{M}$ units of $L$. The implied cost function of each industrial firm is therefore given by:

$$
\pi+w a_{M} x
$$

where $\pi$ and $w$ are the reward to capital and labor, and $x$ is the firm level output.

Physical capital can move between regions but capital owners are immobile. Thus, when pressures arise to concentrate production to one region, capital will move, but its entire reward will be repatriated to its region of origin. Labor, on the other hand, can move freely between sectors but is immobile between regions. Total supply of capital and labor in the economy is fixed, with the nation's endowments denoted by $K_{W}$ and $L_{W}$. Since each industrial variety requires one unit of capital, the capital stock employed in a single region exactly equals the number of varieties produced in a region. Consequently, $n_{j}$ denotes the number of industrial firms in region $j=N, S$, the share of all varieties made in $j$, as well as the stock of capital employed in $j$.

Output in the agricultural sector is traded at no cost, while inter-regional trade in the differentiated output is subject to an iceberg transportation cost. 
Hence, in order to sell one unit of the differentiated good in the other region, $\tau>1$ units need to be shipped.

The representative consumer in each region has preferences according to:

$$
U=C_{M}^{\mu} C_{A}^{1-\mu},
$$

where $\mu \in(0,1)$ and $C_{A}$ is consumption of the homogenous good. Consumption of manufactures enters the utility function through the index $C_{M}$, which is defined by:

$$
C_{M} \equiv\left(\int_{0}^{n_{W}} c_{i}^{\frac{\sigma-1}{\sigma}} d i\right)^{\frac{\sigma}{\sigma-1}},
$$

where $n_{W}=n_{N}+n_{S}$ denotes the number of industrial varieties consumed, fixed by the nation's total supply of capital, $c_{i}$ is the amount of variety $i$ consumed, and $\sigma>1$ is the constant elasticity of substitution between any two varieties.

Assuming that a government can subsidize manufacturing production in both regions at the same time, these subsidies are proportional to the reward to capital and are distributed on a per-firm basis independent of output. Since the one-time fixed cost consists of one unit of $K$, such subsidies represent a subsidy to capital. Let $\pi_{N}\left(\pi_{S}\right)$ denote the before-subsidy reward to capital when producing in the North (South) and let $\theta \equiv \frac{\pi_{N}}{\pi_{S}}=\frac{1+z_{S}}{1+z_{N}}$, where $\theta \in \mathbb{R}_{++}$and $z_{j}$ measures the level of per-firm subsidies proportional to the reward to capital, awarded to a typical firm located in region $j$. Subsidies defined in this way thus entitle the firm to $z_{j}$ units of subsidies per unit of $\pi_{j}$. Clearly, when production in the South is net subsidized, the condition $\theta>1$ must hold, and when production in the North is net subsidized, the condition $0<\theta<1$ must be fulfilled. $\theta=1$ when no net subsidies are distributed.

The subsidies are paid for by lump-sum taxation, and since each unit of labor is identified with an individual (a voter), the per-capita tax can be expressed as a per-unit-of-labor tax. Moreover, the government's budget is always balanced, so that the level of taxation depends on the level of subsidies transferred. Wages are not affected by the subsidies, and since each individual is both a taxpayer and an owner of capital and labor, on net, the agents' total incomes are unaffected by the tax-cum-subsidy. Further, with free capital mobility, those who receive subsidies earn no more than the individuals who receive no subsidies, so netting out the tax-cum-subsidy, the agents' incomes are unaffected by taxation. 
By assumption, there are no savings and therefore expenditures equal disposable income. Consequently, expenditures in region $j, E_{j}$, are given by:

$$
E_{j}=w_{j} L_{j}+\rho_{j} K_{j}-T L_{j}
$$

where $\rho_{j}$ is the subsidy-included return to capital in region $j$, and $T$ is the countrywide lump-sum tax paid by the representative consumer. ${ }^{2}$

\subsection{The Economic Equilibrium}

The unit factor requirement of the homogenous good is one unit of labor $\left(a_{A}=1\right)$. This good is freely traded and since it is also chosen as a numeraire, $p_{A}=w=1$ in both regions.

Each consumer spends a share $\mu$ of his income on manufactures. Maximizing (2.2), subject to (2.3) and the budget constraint, to obtain the demand function in region $j$ for variety $i$ of the differentiated good:

$$
c_{i}=\frac{p_{i}^{-\sigma} \mu E_{j}}{\int_{k=0}^{n_{W}} p_{j k}{ }^{1-\sigma} d k},
$$

where $p_{i}$ is the price of variety $i$. Profit maximization yields: ${ }^{3}$

$$
p=\frac{\sigma}{\sigma-1} w a_{M},
$$

and

$$
p^{*}=\frac{\sigma}{\sigma-1} \tau w a_{M},
$$

for each differentiated commodity sold in the home and export market, respectively. Without any loss of generality, let $a_{M}=\frac{\sigma-1}{\sigma},{ }^{4}$ then using $w=1$

\footnotetext{
${ }^{2}$ All results still hold with a labor income tax, that is, $(1-T) w_{j} L_{j}$.

${ }^{3}$ Differentiating the profit function, $\Pi_{i}=p_{i} c_{i}\left(p_{i}\right)+p_{i}^{*} c_{i}^{*}\left(p_{i}^{*}\right)-\pi-$ $w a_{M}\left(c_{i}\left(p_{i}\right)+c_{i}^{*}\left(p_{i}^{*}\right) \tau\right)$, where $c_{i}^{*}\left(p_{i}^{*}\right)$ is the foreign demand for industry $i$ products, with respect to $p_{i}$ and $p_{i}^{*}$, using $\sigma \equiv-\frac{p_{i}}{c_{i}\left(p_{i}\right)} \frac{\partial c_{i}\left(p_{i}\right)}{\partial p_{i}} \equiv-\frac{p_{i}^{*}}{c_{i}^{*}\left(p_{i}^{*}\right)} \frac{\partial c_{i}^{*}\left(p_{i}^{*}\right)}{\partial p_{i}^{*}}$, solving for the optimal prices gives (2.6) and (2.7).

${ }^{4}$ This assumption is made for algebraic simplicity and does not affect the results, since $a_{M}$ does not enter the location condition. $a_{M}=\frac{\sigma-1}{\sigma}<1$, because $\sigma>1$, implies that less than one unit of labor is needed to produce one unit of the differentiated good.
} 
to obtain the pricing rules for firms in the manufacturing sector: $p=1$ and $p^{*}=\tau$.

Since physical capital is only used in the fixed cost component of industrial production, the reward to capital is the Ricardian surplus of a typical variety, i.e., the operating profit of a variety. With a fixed capital stock and free entry, the reward to capital will be bid up to the point where the entire operating profit goes to capital. Under Dixit-Stiglitz competition, the operating profit is the value of sales divided by $\sigma$; that is, $\pi_{j}=\frac{x_{j}}{\sigma}$, where $x_{j}$ is the scale of production of a representative industrial firm in region $j .^{5}$

National expenditures, $E_{W}$, is written as:

$$
E_{W}=L_{W}+\rho_{W} K_{W}-T L_{W}
$$

where $\rho_{W}$ is determined by the condition $\rho_{W}=\frac{x_{W}}{\sigma}+\frac{T L_{W}}{K_{W}}$. So, with free entry into the industrial sector, the national subsidy-included reward to capital is the sum of the national operating profit and the level of subsidies transferred to a representative manufacturing firm in the economy (since the government's budget is always balanced, and the level of taxation therefore depends on the level of subsidies distributed). Using this and $\frac{x_{W}}{\sigma}=\frac{\mu E_{W}}{K_{W} \sigma}$ (Baldwin et al. [2003]) in (2.8) yields $E_{W}=L_{W}+\frac{\mu E_{W}}{\sigma}$, which implies that:

$$
E_{W}=\frac{\sigma L_{W}}{\sigma-\mu}
$$

Likewise, for region $j$ :

$$
E_{j}=\frac{\sigma L_{j}}{\sigma-\mu}
$$

Combining (2.9) and (2.10) gives $s_{E_{j}} \equiv \frac{E_{j}}{E_{W}}=\frac{L_{j}}{L_{W}}$, where $s_{E_{j}} \in(0,1)$ represents the share of national expenditures of region $j$, and $s_{E_{N}}=1-s_{E_{S}}$. Thus, the relative economic strength of the North is written as: $\lambda \equiv \frac{L_{N}}{L_{S}}=\frac{s_{E_{N}}}{s_{E_{S}}}$.

The domestic and foreign demand function for industry $i$ products, and the optimal prices gives the reward to capital or the operating profit in equilibrium: ${ }^{6}$

\footnotetext{
${ }^{5}$ Free entrance implies that pure profits are eliminated. Employing the profit function from note 2 for a typical manufacturing firm in region $j, w=1, a_{M}=\frac{\sigma-1}{\sigma}, p=1, p^{*}=\tau$, and $x_{j} \equiv c_{j}+c_{j}^{*} \tau$ gives $\pi_{j}=\frac{x_{j}}{\sigma}$.

${ }^{6}$ Using the expressions for the demand functions in $\frac{x_{j}}{\sigma} \equiv \frac{c_{j}+c_{j}^{*} \tau}{\sigma}$, and $p=1, p^{*}=\tau$ yields (2.11) and (2.12).
} 


$$
\pi_{N}=\frac{x_{N}}{\sigma}=\frac{1}{\sigma}\left(\frac{\mu E_{N}}{n_{N}+\phi n_{S}}+\frac{\phi \mu E_{S}}{\phi n_{N}+n_{S}}\right)
$$

and

$$
\pi_{S}=\frac{x_{S}}{\sigma}=\frac{1}{\sigma}\left(\frac{\phi \mu E_{N}}{n_{N}+\phi n_{S}}+\frac{\mu E_{S}}{\phi n_{N}+n_{S}}\right) .
$$

$\tau^{1-\sigma} \equiv \phi \in[0,1]$ is a measure of the freeness of inter-regional trade, where 0 corresponds to infinite trade barriers and 1 represents free trade. Substituting (2.10) into (2.11) and (2.12) to obtain:

$$
\pi_{N}=\frac{a L_{S}}{n_{S}}\left(\frac{\lambda}{v+\phi}+\frac{\phi}{v \phi+1}\right)
$$

and

$$
\pi_{S}=\frac{a L_{S}}{n_{S}}\left(\frac{\lambda \phi}{v+\phi}+\frac{1}{v \phi+1}\right)
$$

where $a \equiv \frac{\mu}{\sigma-\mu} \cdot v \equiv \frac{n_{N}}{n_{S}}$ denotes the number of industrial firms in the North relative to industrial firms located in the South. With one unit of capital per variety, $v$ is also defined as the relative size of the capital stock employed in the North, or the relative number of varieties produced in the North.

With perfect capital mobility, and when manufacturing production takes place in both regions, the location condition requires that capital employed in the North must earn the same subsidy-included rate of return as capital in the South: $\pi_{N}=\pi_{S} \theta$. Given (2.13) and (2.14), the distribution of industry solving this condition is:

$$
v(\phi, \theta, \lambda)=\frac{\lambda(1-\theta \phi)-\phi(\theta-\phi)}{\theta-\phi-\lambda \phi(1-\theta \phi)} .
$$

Let $\theta=1$ (i.e., no net subsidies are transferred) and differentiate (2.15) with respect to $\lambda$ :

$$
\left.\frac{\partial v}{\partial \lambda}\right|_{\theta=1}=\frac{1-\phi^{2}}{(\lambda \phi-1)^{2}}>1
$$

for an interior solution (that is, $\forall \phi<\frac{1}{\lambda}$ ). (2.16) demonstrates the home market effect. Thus $v$ increases more than proportionate to $\lambda \forall \phi \in(0,1)$, and this effect becomes stronger as trade barriers are reduced (so-called home 
market magnification, due to Krugman [1991]). This means that even if one region is just slightly larger than the other, it will obtain the entire manufacturing industry if transaction costs are sufficiently low.

To illustrate the effect of subsidies on the geographical equilibrium, differentiate (2.15) with respect to $\theta$ :

$$
\frac{\partial v}{\partial \theta}=-\frac{\lambda\left(\phi^{2}-1\right)^{2}}{(\theta-\phi-\lambda \phi(1-\theta \phi))^{2}}<0,
$$

$\forall \phi \in[0,1)$. (2.17) implies that the location of manufacturing activities in the North is decreasing in subsidies distributed to the South. By differentiating (2.17) with respect to $\phi$ it is clear that the sign of this derivative is ambiguous and depends on the relative sizes of $\lambda, \phi$ and $\theta$.

The welfare of a representative individual is a function of the income and the price index prevailing in the region of residence. Given (2.2), the indirect utility functions are (see Appendix A.1 for details):

$$
\begin{aligned}
& V_{N}(\phi, \theta)=\ln (1+a)+\frac{\mu}{\sigma-1} \ln \left(\frac{\phi+v}{1+v}\right), \\
& V_{S}(\phi, \theta)=\ln (1+a)+\frac{\mu}{\sigma-1} \ln \left(\frac{1+v \phi}{1+v}\right),
\end{aligned}
$$

for an agent in the North and the South, respectively. $V_{N}>V_{S}$ if and only if $v>1$, that is, if $n_{N}>n_{S} \cdot{ }^{7}$ Moreover, it is straightforward to verify that $\frac{\partial V_{N}}{\partial v}>0$ and $\frac{\partial V_{S}}{\partial v}<0$. Further, it is shown in Appendix A.2 that $\frac{\partial V_{N}}{\partial \phi}>0$, while $\frac{\partial V_{S}}{\partial \phi}>0$ if $s_{N}>\frac{\partial s_{N}}{\partial \phi}(1-\phi)$, where $s_{N}=\frac{v}{1+v} \in(0,1)$, and $1-s_{N}=s_{S}=\frac{1}{1+v}$. Consequently, individual welfare increases in the number of firms located in the agent's region and in the level of economic integration, since this lead to a decrease in consumer prices of manufactures and save the transportation cost facing the consumer, when lower trade costs have to be paid on fewer imports. Trade liberalization benefits citizens in the South when more firms are located in the North (that is, when $s_{N}$ is higher), for more liberalized trade (i.e., when $\phi$ is higher), and when fewer firms relocate to the North in response to a given shift in $\phi$ (for lower $\frac{\partial s_{N}}{\partial \phi}$ ). The reason is that this imply lower consumer prices and larger transportation cost savings. It is henceforth assumed that the South always gains from trade

$$
{ }^{7} V_{N}-V_{S}=\frac{\mu}{\sigma-1}\left(\ln \left(\frac{\phi+v}{1+v}\right)-\ln \left(\frac{1+v \phi}{1+v}\right)\right)=\frac{\mu}{\sigma-1} \ln \left(\frac{\phi+v}{1+v \phi}\right)>0 \text { if } v>1 \text {, or } n_{N}>n_{S} .
$$


liberalization, thus $s_{N}>\frac{\partial s_{N}}{\partial \phi}(1-\phi)$ is taken to hold throughout the rest of the paper.

Also, it is shown in Appendix A.2 that $\frac{\partial V_{N}}{\partial \phi}<\frac{\partial V_{S}}{\partial \phi}$ if $s_{N}>\frac{1+\frac{\partial s_{N}}{\partial \phi}\left(1-\phi^{2}\right)}{2}$, i.e., if $s_{S}<\frac{1-\frac{\partial s_{N}}{\partial \phi}\left(1-\phi^{2}\right)}{2}$. The welfare gains of trade liberalization is thus relatively larger in the South if this region is smaller than a threshold value, when fewer firms relocate to the larger region as trade protection falls, and for low trade costs. Under these conditions, citizens in the smaller region, where fewer varieties are produced, save relatively more on the transportation cost as trade is liberalized without losing manufacturing production to the North at a high rate; this makes the welfare gains from economic integration of individuals in the South relatively larger.

It can further be established that $\frac{\partial V_{N}}{\partial \theta}<0$ and $\frac{\partial V_{S}}{\partial \theta}>0$. Hence, increasing the allocation of subsidies to the South decreases (increases) the number of industrial firms in the North (South), which decreases (increases) individual welfare of the North (South) through the price index.

With the economic model specified, it is now time to introduce the political game that aims at determining the direction and size of the subsidy.

\section{The Political Model}

Thus far, the regional policy variable, $\theta$, has been taken as exogenous in the theoretical setting. It shall now be determined by a specific process of participation in elections, where agents are motivated to vote out of a sense of ethical obligation. The electoral framework considered is a modification of the model by Feddersen and Sandroni (2006) which, in turn, is based on the work of Harsanyi $(1977,1980,1992)$.

\subsection{The Basic Setting}

Elections involve the two candidates, or parties, $N$ and $S$. Each unit of labor is identified with a voter, hence the size of the electorate, which is normalized to unity, is $L_{W}=L_{N}+L_{S}=1$. Voters must either vote for candidate $N$, for candidate $S$, or abstain. The election is decided by majority rule. Each agent has a cost of voting given by $\bar{c}>0$, multiplied by an independent uniformly distributed random variable over the interval $(0,1)$. This cost can be thought of as, for example, the time spent in the process of voting. Assume that each 
agent's cost of voting is independent of any other random variable in the model, and that each agent knows her own realized voting cost, but not the realization of other agents' costs.

Voters in the North prefer candidate $N$ and voters in the South prefer candidate $S . L_{N}>L_{S}$ since $\lambda>1$, so voters in the South are a minority. Formally, political preferences are given by:

$$
V_{N} P-\Phi,
$$

for the typical voter in the North, and:

$$
V_{S}(1-P)-\Phi,
$$

for the representative voter in the South. $P$ is the probability that candidate $N$ wins the election, $V_{j}$ is given by (2.18) and (2.19) and measures the importance of the election, and $\Phi$ is the expected social cost of voting. Holding everything else constant, the higher the welfare, $V_{j}$, from regional policy, the higher the expected social cost that agents in region $j$ would be willing to trade for an increase in the chances that their favored candidate wins. Thus, $V_{j}$ captures the importance of the difference between the two candidates relative to the social cost of voting. All agents prefer this social cost to be minimized.

Let a rule profile be the cutoff points $\alpha_{j} \in[0,1]$, which specify that agents in region $j$ with costs below $\alpha_{j} \bar{c}$ should vote for candidate $j$, and agents with costs above $\alpha_{j} \bar{c}$ should abstain. Some agents (called ethical agents) receive a payoff $D>\bar{c}$ for acting according to their rule profile and therefore always do so. Other agents receive zero payoff from their rule profile; they always prefer to abstain. The fraction of ethical agents in each region, $\tilde{q}_{N}$ and $\tilde{q}_{S}$, are independent and uniformly distributed over $[0,1]$.

Agents face a trade-off when determining which rule to follow. A higher cutoff $\alpha_{j}$ implies a higher probability that the favored candidate is elected, but also a higher social cost. Assume that ethical agents follow the rule profile $\left(\alpha_{N}, \alpha_{S}\right)$. Then the expected social cost of voting is:

$$
\Phi\left(\alpha_{N}, \alpha_{S}\right)=\bar{c}\left(L_{N} E\left(\tilde{q}_{N}\right) \int_{0}^{\alpha_{N}} y d y+L_{S} E\left(\tilde{q}_{S}\right) \int_{0}^{\alpha_{S}} y d y\right)=\frac{\bar{c}}{4}\left(L_{N} \alpha_{N}^{2}+L_{S} \alpha_{S}^{2}\right)
$$




\subsection{The Voting Equilibrium}

Candidate $N$ is elected if a majority of the votes is received. Under the assumption that a fraction $\alpha_{j}>0$ of the ethical agents in region $j$ votes, ${ }^{8}$ candidate $N$ wins if:

$$
L_{N} \alpha_{N} \tilde{q}_{N} \geq L_{S} \alpha_{S} \tilde{q}_{S}
$$

that is, if:

$$
\frac{\tilde{q}_{S}}{\tilde{q}_{N}} \leq \lambda \frac{\alpha_{N}}{\alpha_{S}}
$$

Candidate $N$ is therefore elected with probability:

$$
P\left(\alpha_{N}, \alpha_{S}\right)=F_{\frac{\tilde{q}_{S}}{\tilde{q}_{N}}}\left(\lambda \frac{\alpha_{N}}{\alpha_{S}}\right),
$$

where $F_{\tilde{x}}(x) \equiv P(\tilde{x} \leq x)$ is the cumulative distribution function of a random variable $\tilde{x}$.

Analogously, candidate $S$ wins the election with probability:

$$
1-P\left(\alpha_{N}, \alpha_{S}\right)=F_{\frac{\tilde{q}_{N}}{\tilde{q}_{S}}}\left(\frac{\alpha_{S}}{\lambda \alpha_{N}}\right) .
$$

Given the political preferences, i.e., (3.1) and (3.2), the ethical agents who act according to their rule profile receive the payoff:

$$
\begin{gathered}
R_{N}\left(\alpha_{N}, \alpha_{S}\right)=V_{N} P\left(\alpha_{N}, \alpha_{S}\right)-\Phi\left(\alpha_{N}, \alpha_{S}\right), \\
R_{S}\left(\alpha_{N}, \alpha_{S}\right)=V_{S}\left(1-P\left(\alpha_{N}, \alpha_{S}\right)\right)-\Phi\left(\alpha_{N}, \alpha_{S}\right),
\end{gathered}
$$

in the North and the South, respectively.

In a consistent rule profile $\left(\alpha_{N}^{*}, \alpha_{S}^{*}\right)$, no agent concludes that the ethical agents of the same region can achieve a better outcome by following an alternative rule. Formally:

$$
R_{N}\left(\alpha_{N}^{*}, \alpha_{S}^{*}\right) \geq R_{N}\left(\alpha_{N}, \alpha_{S}^{*}\right)
$$

and

${ }^{8}$ The level of turnout in a region must be strictly positive. Otherwise, voters in the other region can win the election at a infinitesimally small social cost. 


$$
R_{S}\left(\alpha_{N}^{*}, \alpha_{S}^{*}\right) \geq R_{S}\left(\alpha_{N}^{*}, \alpha_{S}\right) .
$$

Let $\bar{F}$ and $f$ be the cumulative distribution function and density function of $\frac{\tilde{q}_{S}}{\tilde{q}_{N}}$ and $\frac{\tilde{q}_{N}}{\tilde{q}_{S}}$. Following Feddersen and Sandroni (2006), these functions are given by:

$$
\begin{gathered}
\bar{F}(u)=\frac{u}{2} \quad \text { if } u \leq 1, \\
f(u)=\frac{1}{2} \quad \text { if } u \leq 1, \\
\bar{F}(u)=1-\frac{1}{2 u} \quad \text { if } u \geq 1, \\
f(u)=\frac{1}{2 u^{2}} \quad \text { if } u \geq 1,
\end{gathered}
$$

where (3.13) and (3.15) imply that $f(u)=f\left(\frac{1}{u}\right) \frac{1}{u^{2}}$.

Substituting (3.6) and (3.3) into (3.1), taking the derivative of resulting expression with respect to $\alpha_{N}$, using $f(u)=f\left(\frac{1}{u}\right) \frac{1}{u^{2}}$, yields the following first order condition for an interior equilibrium: ${ }^{9}$

$$
V_{N} f\left(\frac{\alpha_{S}}{\lambda \alpha_{N}}\right) \frac{\alpha_{S}}{\lambda \alpha_{N}^{2}}-\frac{\bar{c}}{2} L_{N} \alpha_{N}=0 .
$$

Using (3.7) and (3.3) in (3.2), differentiating the resulting expression with respect to $\alpha_{S}$ to obtain the first order condition for an interior equilibrium:

$$
V_{S} f\left(\frac{\alpha_{S}}{\lambda \alpha_{N}}\right) \frac{1}{\lambda \alpha_{N}}-\frac{\bar{c}}{2} L_{S} \alpha_{S}=0 .
$$

Dividing (3.16) with (3.17) gives: $u=\frac{\alpha_{S}}{\lambda \alpha_{N}}=\sqrt{\frac{\omega}{\lambda}}<1$, where $\omega \equiv \frac{V_{S}}{V_{N}}<1$ since $V_{N}>V_{S}$, and $\lambda>1$. Therefore, $f\left(\frac{\alpha_{S}}{\lambda \alpha_{N}}\right)=\frac{1}{2}$ by (3.13), which simplifies the first order conditions and gives a unique solution for the turnout in the North and the South:

$$
\alpha_{N}^{*}=\sqrt[4]{\frac{V_{N} V_{S} L_{S}}{L_{N}^{3}}} \frac{1}{\sqrt{\bar{c}}}
$$

${ }^{9}$ Using $f(u)=f\left(\frac{1}{u}\right) \frac{1}{u^{2}} \Leftrightarrow f\left(\lambda \frac{\alpha_{N}}{\alpha_{S}}\right)=f\left(\frac{\alpha_{S}}{\lambda \alpha_{N}}\right) \frac{\alpha_{S}^{2}}{\lambda^{2} \alpha_{N}^{2}}$ gives (3.16). 
and

$$
\alpha_{S}^{*}=\sqrt[4]{\frac{V_{S}^{3}}{V_{N} L_{N} L_{S}}} \frac{1}{\sqrt{\bar{c}}} .
$$

Let $t \equiv \frac{\alpha_{S}^{*}}{\alpha_{N}^{*}}$ be the relative turnout level of the South, then:

$$
t(\phi, \theta)=\sqrt{\lambda \omega}
$$

Since $\lambda>1$ and $\omega<1$, the turnout level of the South is higher than in the North if the relative size of the electorate of the North is larger than the relative importance of the election to the North voters; that is, if $\lambda>\frac{1}{\omega}=\frac{V_{N}}{V_{S}}$.

The region hosting the minority has a political advantage from a voter turnout perspective, a property which is due to the South's relatively lower social cost of increasing the participation rate. To see this, note that changes in the turnout lead to a ratio of marginal costs of voting given by: $\frac{\partial \Phi}{\partial \alpha_{S}^{*}} / \frac{\partial \Phi}{\partial \alpha_{N}^{*}}=$ $\frac{\alpha_{S}^{*}}{\lambda \alpha_{N}^{*}}=\sqrt{\frac{\omega}{\lambda}}<1$. Clearly, a higher $\lambda$ (that is, increasing the relative size of the electorate in the North) decreases the relative marginal cost of the South of mobilizing extra voters.

It is shown in Appendix A.3 that $\frac{\partial t}{\partial \phi}>0$ if $s_{S}<\frac{1-\frac{\partial s_{N}}{\partial \phi}\left(1-\phi^{2}\right)}{2}$; thus, by inspection of (3.20):

Proposition 1: In the voting equilibrium, the relative turnout level of the South, $t$, is increasing in the relative economic strength of the North, $\lambda$ (that is, in the relative size of the electorate in the North), in the relative welfare level of a representative voter in the South, $\omega$, and in the level of regional integration, $\phi$, if the South is smaller than the above threshold.

The reason for these results can be explained as follows. First, increasing the relative size of the electorate in the North decreases the relative marginal cost of increasing the turnout in the South. Second, as $V_{j}$ increases, so does the importance of the election to the voters of region $j$ : the higher the welfare from regional policy, the higher the expected social cost that agents in region $j$ would be willing to trade for an increase in the chances that their favored candidate wins. In other words, when $\omega$ increases, so does the relative importance that voters in region $S$ assign to their candidate winning the election; this in turn increases the relative turnout of the South. 
Third, if $s_{S}<\frac{1-\frac{\partial s_{N}}{\partial \phi}\left(1-\phi^{2}\right)}{2}$, increasing $\phi$ increases the relative welfare level of the South, $\omega$, since in this case, the smaller region saves relatively more on the transportation cost as trade is liberalized. Hence, as trade becomes freer, voters residing in a factor scarce region are willing to incur a relatively higher social cost of voting to see their preferred regional policy implemented, which increases their relative turnout.

Using (3.20) in (3.6) gives the probability that candidate $N$ is elected:

$$
P=\bar{F}\left(\frac{\lambda}{t}\right) .
$$

Treating the relative turnout level of the South as a parameter, noting that changes in $t$ are induced by changes in the primitive parameters of the model, and that $\frac{\lambda}{t}=\sqrt{\frac{\lambda}{\omega}},(3.21)$ implies that increasing the relative turnout level of the South decreases the probability of candidate $N$ being elected. Increasing the relative size of the electorate in the North increases this probability.

To solve for the political equilibrium subsidy, (3.21) is maximized with regard to $z_{j}$, which gives (see Appendix A.4 for details):

$$
\theta^{*}=\left(\frac{\lambda^{2}-t^{2} \phi}{\lambda^{2} \phi-t^{2}}\right)^{2}
$$

It is shown in Appendix A.5 that there exists a convergent electoral equilibrium where both candidates, $N$ and $S$, choose the same policy, given by (3.22). Formally, they share the same first-order condition, and do not themselves have preferences over policy.

Since $\theta^{*}>1$ (see Appendix A.6 for details), it follows that the relatively smaller region is net subsidized. Intuitively, in equilibrium both candidates maximize the probability of winning, taking into account the relative turnout level and the size of electorate $N$ and $S$. By (A.17) and (A.23) in Appendix A.4 and A.5, this is equivalent to maximizing a weighted social welfare function, where the weights correspond to how regional voter turnout responds to changes in $\theta^{*}$, mediated through the welfare functions, $V_{j}$. It can be shown that $\left|\frac{\partial t}{\partial V_{N}} / \frac{\partial t}{\partial V_{S}}\right|=\omega<1$, hence voters in the South reward policy-induced welfare changes with a relatively higher turnout compared to voters in the North. Both candidates therefore net subsidize manufacturing production in the South, as more votes can be gained by announcing a policy closer to the bliss point of the electorate in this region. 
To derive comparative-static properties of the voting equilibrium defined by (3.22), the location decision facing manufacturing firms needs to be specified. This makes it possible to solve for the model as a whole, that is, for the distribution of industry implied by the voting equilibrium, $v^{*}$. To this we turn next.

\section{The Political Economy Equilibrium}

Consider the following two-stage game. In the first stage, firms relocate between the regions in response to the level of economic integration $(\phi)$ and the regional shares of total expenditures $(\lambda)$, i.e., the relative economic strength of the North, or the relative size of the electorate of the North. In the second and final stage, the voting process specified in Section 3 determines the regional allocation of net subsidies $\left(\theta^{*}\right)$ in equilibrium.

A subgame perfect equilibrium outcome of this game is solved by backward induction. In the final stage, the distribution of industry is already determined by the first-stage relative economic strength of the North and the freeness of inter-regional trade. From the perspective of the second stage, and by combining (3.22), (3.20), $\omega \equiv \frac{V_{S}}{V_{N}},(2.18)$ and (2.19), the government must take the first-stage equilibrium into account when net subsidies are distributed. This implies that (3.22) can be reproduced as:

$$
\theta^{*}=f\left(\lambda, t\left(V_{N}\left(\phi, v^{*}(\lambda, \phi)\right), V_{S}\left(\phi, v^{*}(\lambda, \phi)\right), \lambda\right), \phi\right),
$$

where the number of industrial firms in the second stage in the North and the South depends on the relocation decisions made in the first stage, and thus implicitly on the relative economic strength of the North and the level of inter-regional trade barriers, exogenously determined in the first stage: $v^{*}(\lambda, \phi)$.

Defining $Z_{N} \equiv 1+z_{N}^{*}=\frac{\lambda^{2} \phi-t^{2}}{\lambda^{2}-t^{2} \phi}$ and $Z_{S} \equiv 1+z_{S}^{*}=\frac{\lambda^{2}-t^{2} \phi}{\lambda^{2} \phi-t^{2}}$, rewriting (4.1):

$$
\theta^{*}=f\left(Z_{j}\left(\lambda, t\left(V_{N}\left(\phi, v^{*}(\lambda, \phi)\right), V_{S}\left(\phi, v^{*}(\lambda, \phi)\right), \lambda\right), \phi\right)\right) .
$$

Treating the relative turnout level of the South as a parameter, taking the derivative of (4.2) with respect to $t$ yields:

$$
\frac{\partial \theta^{*}}{\partial t}=\frac{\partial f}{\partial Z_{N}} \frac{\partial Z_{N}}{\partial t}+\frac{\partial f}{\partial Z_{S}} \frac{\partial Z_{S}}{\partial t} \geq 0
$$


since $\frac{\partial f}{\partial Z_{N}}<0, \frac{\partial Z_{N}}{\partial t}=-\frac{2 t \lambda^{2}\left(1-\phi^{2}\right)}{\left(\lambda^{2}-t^{2} \phi\right)^{2}} \leq 0, \frac{\partial f}{\partial Z_{S}}>0$ and $\frac{\partial Z_{S}}{\partial t}=\frac{2 t \lambda^{2}\left(1-\phi^{2}\right)}{\left(t^{2}-\lambda^{2} \phi\right)^{2}} \geq 0$. Thus, increasing the relative turnout of the South increases net subsidies distributed to the South; more generally, this holds for any region $j$. The intuition is simple: the citizens have the votes that the politicians need to win the election. The parties are therefore willing to reward citizens for turning out to vote, since political participation is a resource when the parties maximize their probability of winning, and more votes can be gained in a region with a higher turnout. For this reason, citizens in the South are rewarded with more subsidies when they vote at higher rates.

Totally differentiating (4.2) with respect to $\lambda$, it is shown in Appendix A.7 that $\frac{\partial \theta^{*}}{\partial \lambda} \leq 0$. Hence, increasing the relative size of the electorate in the North increases subsidies distributed to the North; this holds for any region $j$. The value of the derivative depends on the magnitude of two opposing effects. On the one hand, as the electorate of the North becomes larger, the turnout of the South increases by (3.20), and this increases the level of subsidies allocated to the South by (4.3). On the other hand, by increasing the number of votes to be gained, the larger electorate makes citizens in the North more attractive to the candidates, who thus tilt their policy in the direction desired by these voters; that is, they optimally decrease $\theta^{*}$. As shown in Appendix A.7, the latter effect dominates the former, hence the allocation of subsidies distributed to the North on net increases (i.e., $\theta^{*}$ decreases) as $\lambda$ increases.

Taking the total derivative of (4.2) with respect to $\phi$, it is shown in Appendix A.8 that $\frac{\partial \theta^{*}}{\partial \phi} \geq(\leq) 0$ if $\frac{\partial \theta^{*}}{\partial t} \frac{\partial t}{\partial \phi}+\frac{\partial f}{\partial Z_{N}} \frac{\partial Z_{N}}{\partial \phi}+\frac{\partial f}{\partial Z_{S}} \frac{\partial Z_{S}}{\partial \phi} \geq(\leq) 0$. The first term, $\frac{\partial \theta^{*}}{\partial t} \frac{\partial t}{\partial \phi} \geq 0$ (if the South is smaller than the threshold value, such that $\frac{\partial t}{\partial \phi}>0$ ), captures the increase in subsidies distributed to the South as the relative turnout of this region increases in response to trade liberalization. The second and third term, $\frac{\partial f}{\partial Z_{N}} \frac{\partial Z_{N}}{\partial \phi}+\frac{\partial f}{\partial Z_{S}} \frac{\partial Z_{S}}{\partial \phi} \leq 0$, measures the decrease in $\theta^{*}$ that results from relocation to the relatively larger region due to the home market magnification effect when trade costs are reduced (that is, $v^{*}$ increases). This increases $V_{N}$ (because $\partial V_{N} / \partial v^{*}>0$ ) and decreases $V_{S}$ (since $\partial V_{S} / \partial v^{*}<0$ ) which decreases $\omega$ (since $\omega=V_{S} / V_{N}$ ). As $\omega$ decreases, the higher the social cost of voting the citizens in the North are willing to trade for an increase in the probability of their preferred party winning. This decreases $t$, by (3.20), and the level of subsidies distributed to the South, by (4.3), as trade becomes freer. If the first (second and third) term dominates the second and third (first), $\frac{\partial \theta^{*}}{\partial \phi} \geq 0\left(\frac{\partial \theta^{*}}{\partial \phi} \leq 0\right)$. Note however that $\theta^{*}>1 \forall \phi$, 
hence the smaller region is always net subsidized.

These results are summarized as follows:

Proposition 2: The level of subsidies distributed to the South is increasing in the relative turnout of the South, decreasing in the relative size of the electorate of the North, and increasing (decreasing) in the level of regional integration if $\frac{\partial \theta^{*}}{\partial t} \frac{\partial t}{\partial \phi}+\frac{\partial f}{\partial Z_{N}} \frac{\partial Z_{N}}{\partial \phi}+\frac{\partial f}{\partial Z_{S}} \frac{\partial Z_{S}}{\partial \phi} \geq(\leq) 0$. That is, $\frac{\partial \theta^{*}}{\partial t} \geq 0$, $\frac{\partial \theta^{*}}{\partial \lambda} \leq 0$, and $\frac{\partial \theta^{*}}{\partial \phi} \geq(\leq) 0$ if $\frac{\partial \theta^{*}}{\partial t} \frac{\partial t}{\partial \phi}+\frac{\partial f}{\partial Z_{N}} \frac{\partial Z_{N}}{\partial \phi}+\frac{\partial f}{\partial Z_{S}} \frac{\partial Z_{S}}{\partial \phi} \geq(\leq) 0$.

From the perspective of the first stage, and through backward induction, the firms in region $j$ must take the second-stage equilibrium into account when relocation decisions are made. Hence, the first-stage equilibrium is affected by the relative turnout of region $j$ determined in the second stage, which decides the direction and size of government net transfers. Consequently, using (3.22) in (2.15) yields the distribution of industry, implied by the voting equilibrium, as a function of the relative turnout level of the South, the relative size of the electorate of the North, and the level of regional integration:

$$
v^{*}=f(t, \lambda, \phi) .
$$

Taking the derivative of (4.4) with respect to $t$ it can be established that (proof in Appendix A.9):

Proposition 3: Increasing the relative turnout level of region $j$ increases the number of firms located in this region. That is, $\frac{\partial v^{*}}{\partial t} \leq 0$.

As intuition might suggest, a higher turnout in region $j$ increases the level of subsidies allocated to this region by (4.3). This increases the subsidyincluded relative return to capital in $j$ by the location condition $\left(\pi_{N}=\pi_{S} \theta^{*}\right)$ and accordingly, by (2.17), the number of firms located in $j$.

By totally differentiating (4.4) with respect to $\lambda$ it can also be shown that (proof in Appendix A.10):

Proposition 4: The introduction of voting over regional policy implies higher agglomeration economies in the larger region compared to the location equilibrium without voting if $\zeta<1$, but reversed agglomeration if $\zeta>1$. That is, $\frac{\partial v^{*}}{\partial \lambda}>\frac{\partial f}{\partial \lambda}>0$ if $\zeta<1$, and $\frac{\partial v^{*}}{\partial \lambda}<0<\frac{\partial f}{\partial \lambda}$ if $\zeta>1$. 
$\zeta \equiv \frac{\partial f}{\partial \theta^{*}}\left(\frac{\partial \theta^{*}}{\partial Z_{N}} \frac{\partial Z_{N}}{\partial t}+\frac{\partial \theta^{*}}{\partial Z_{S}} \frac{\partial Z_{S}}{\partial t}\right)\left(\frac{\partial t}{\partial V_{N}} \frac{\partial V_{N}}{\partial v^{*}}+\frac{\partial t}{\partial V_{S}} \frac{\partial V_{S}}{\partial v^{*}}\right) \geq 0$ measures how a marginal change in $\lambda$ affects $v^{*}$ through its influence on the number of firms in the second stage, which in turn, by (4.2), affects $\theta^{*}$ via $V_{j}, t$, and $Z_{j}$. Note that $\frac{\partial v^{*}}{\partial \lambda}(1-\zeta)=$

$\frac{\partial f}{\partial \lambda}+\frac{\partial f}{\partial \theta^{*}}\left(\frac{\partial \theta^{*}}{\partial Z_{N}}\left(\frac{\partial Z_{N}}{\partial \lambda}+\frac{\partial Z_{N}}{\partial t} \frac{\partial t}{\partial \lambda}\right)+\frac{\partial \theta^{*}}{\partial Z_{S}}\left(\frac{\partial Z_{S}}{\partial \lambda}+\frac{\partial Z_{S}}{\partial t} \frac{\partial t}{\partial \lambda}\right)\right)$, where the second term on the right-hand side is positive. Hence, a given shift in $\lambda$ increases agglomeration in the North compared to the equilibrium without voting over regional policy (captured by the term $\frac{\partial f}{\partial \lambda}$ ) if $\zeta<1$, but reverses this process and increases the number of firms located in the South if $\zeta>1$. The reason for this result can be explained as follows. $\frac{\partial v^{*}}{\partial \lambda}$ measures how firms locate in response to changes in $\lambda$ in the first stage of the political-economy game, taking into account the location condition. $\zeta \frac{\partial v^{*}}{\partial \lambda}$, on the other hand, captures the location effect of a larger electorate in the North mediated through $\theta^{*}$, which is determined by the voting process in the second stage of the game. As $\lambda$ increases, and for $\zeta<1(\zeta>1)$, manufacturing production shifts to the North by less (more) than what is optimally implied by the equilibrium location condition. This means that any forward-looking firm can increase its subsidy-included rate of return to capital by relocating to the North (South) in the first stage, and hence $\frac{\partial v^{*}}{\partial \lambda}>\frac{\partial f}{\partial \lambda}>0 \forall \zeta<1\left(\frac{\partial v^{*}}{\partial \lambda}<0<\frac{\partial f}{\partial \lambda} \forall \zeta>1\right)$. $1-\zeta$ can therefore be interpreted as a condition according to which firms adjust their location of manufacturing activity in the first-stage equilibrium, taking into account the expected subsidy-included regional return to capital.

Let $\frac{\partial V_{N}}{\partial \phi} / \frac{\partial V_{S}}{\partial \phi} \geq V_{N} / V_{S}$, which is satisfied if the welfare gains from trade liberalization in the South are small ${ }^{10}$ i.e., if the voters in the South are less willing to incur a higher social cost of voting to see their preferred regional policy implemented as trade costs are lowered. Clearly, this is a conservative assumption for deriving reversed agglomeration, since it implies that the relative turnout of the smaller region, and the net subsidies distributed to the South, increases by a relatively small factor when trade is liberalized; in turn decreasing the relative benefit of locating to this region. Then it can be shown by taking the total derivative of (4.4) with respect to $\phi$ that (proof in Appendix A.11):

Proposition 5: The introduction of voting over regional policy implies $10 \frac{\partial V_{N}}{\partial \phi} / \frac{\partial V_{S}}{\partial \phi}=\frac{\left(1-s_{N}(1-\phi)\right)\left(1-s_{N}+\frac{\partial s_{N}}{\partial \phi}(1-\phi)\right)}{\left(s_{N}-\frac{\partial s_{N}}{\partial \phi}(1-\phi)\right)\left(s_{N}(1-\phi)+\phi\right)}>0$ if $\frac{\partial V_{S}}{\partial \phi}>0$, that is, if $s_{N}>\frac{\partial s_{N}}{\partial \phi}(1-\phi)$. 
higher agglomeration economies in the larger region compared to the location equilibrium without voting if $\zeta<1$, but reversed agglomeration if $\zeta>1$. That is, $\frac{\partial v^{*}}{\partial \phi}>\frac{\partial f}{\partial \phi}>0$ if $\zeta<1$, and $\frac{\partial v^{*}}{\partial \phi}<0<\frac{\partial f}{\partial \phi}$ if $\zeta>1$.

The mechanism behind Proposition 5 can be described in the following way. When trade becomes freer, the benefit of producing in the region hosting the larger number of consumers is less crucial for the location decisions of firms. Hence, a regional policy that net subsidizes production in the South as trade is liberalized - $\theta^{*}>1 \forall \phi$ as shown in Appendix A.6 - decreases the market-access advantage of producing in the relatively larger region in proportion to deepened market integration. For a given $\lambda$, subsidies to manufacturing production and, as a result, the relative political participation rate, are therefore relatively more efficient in attracting industrial activity as economic integration increases. However, the political-economy equilibrium given by (4.4) requires that the relocation of manufacturing activities takes place up until all the gains from government subsidies are exhausted; in other words, that firms internalize the subsidy-included relative return to capital when location decisions are made in the first stage of the political-economy game. In this case, $\zeta$ captures how a marginal change in $\phi$ affects $v^{*}$ through its influence on the number of firms in the second stage, which by (4.2) affects $\theta^{*}$ via $V_{j}, t$, and $Z_{j}$. As $\phi$ increases, and when $\zeta<1(\zeta>1)$, firms locate less (more) production to the North than what is optimally implied by the location condition. Hence, firms can increase their subsidy-included rate of return by relocating to the North (South) in the first stage. Consequently, $\frac{\partial v^{*}}{\partial \phi}>\frac{\partial f}{\partial \phi}>0$ if $\zeta<1$, and $\frac{\partial v^{*}}{\partial \phi}<0<\frac{\partial f}{\partial \phi}$ if $\zeta>1$, where $\frac{\partial f}{\partial \phi}$ captures the agglomeration effect from liberalized trade without voting over regional policy.

Figure 1 shows how the share of industry in the North, $s_{N}^{*}=\frac{v^{*}}{1+v^{*}} \in$ $(0,1)$, where $s_{S}^{*} \equiv 1-s_{N}^{*}$, changes as trade barriers are reduced, using the following parameter values: $\mu=0.9, \sigma=7.1$ and $\lambda=1.5 .{ }^{11}$ For comparison, the graph also displays as a dashed curve, the location equilibrium without voting, denoted $\left.s_{N}\right|_{\theta^{*}=1}$, where no net subsidies are transferred (that is, where $\theta^{*}=1$ ), also using $\lambda=1.5$.

Starting from autarky in Figure 1, the share of industry in the North implied by the voting equilibrium is monotonically decreasing as trade is

\footnotetext{
${ }^{11} \mu=0.9$ and $\sigma=7.1$ are the averages of the implied values estimated across U.S. counties 1970-1980 and 1980-1990 by Hanson (2005).
} 
Figure 1: The share of industry in the North for different degrees of openness

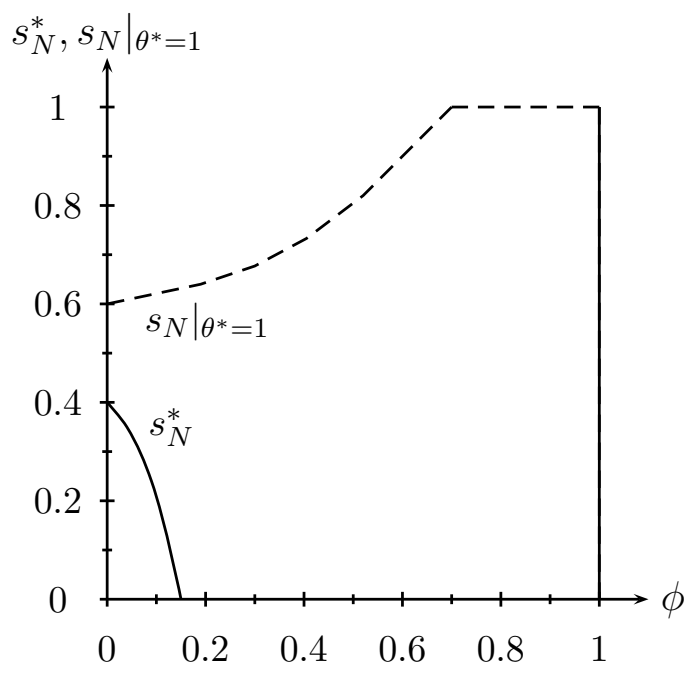

liberalized. Thus, for the parameter values assumed, regional integration results in a shift of manufacturing production to the region with relative factor scarcity, and hence $\frac{\partial v^{*}}{\partial \phi}<0<\frac{\partial f}{\partial \phi} \forall \phi$. That is, for the manufacturing sector, the benefit of a government policy directed towards subsidizing the establishment of industrial firms in the economically smaller region, outweighs the market-access advantage of producing in the larger region. At some point on the integration path, the South obtains the entire manufacturing industry and consequently, the model features a reversed core-periphery equilibrium like in the static set-up of Robert-Nicoud and Sbergami (2004). However, in a dynamic version of their model, this prediction would not be valid since, in such a setting, forward-looking firms will not relocate until all the economic activity is agglomerated in the South, because this would imply that $\theta^{*}<1$ (since the North then becomes the smaller region); thus, any firm could have increased its subsidy-included rate of return by relocating to the North. Therefore, their reversed core-periphery equilibrium is not consistent with subgame perfection. In contrast, the equilibrium considered here is subgame perfect, and therefore firms take the expected subsidy-included relative return to capital into account when relocation decisions are made in the first stage of the political-economy game. This means that production shifts towards the relatively smaller region until all the gains from subsidies are exhausted. It is shown in Appendix A.6 that $\theta^{*}>1 \forall \phi$; consequently, firms 
can increase their subsidy-included return to capital by shifting production to the South until this region obtains the entire manufacturing industry.

We now turn to an examination of the empirical implications of the model.

\section{Empirical Framework}

This section tests one of the main prediction of the model using Swedish county-level data. Specifically, Proposition 3 is tested, which states that the number of firms in region $j$ is increasing in the relative turnout of $j$.

Proposition 3 is based on three testable premises: (1) from equation (2.17), the location of industry in region $j$ is increasing in firm subsidies distributed to $j$; (2) by equation (4.3), regions that vote at higher rates receive more firm subsidies; (1) and (2) imply (3), that the location of industry in $j$ is increasing in the voter turnout of $j$.

The empirical analysis includes a comparison with the central predictions of the model of Robert-Nicoud and Sbergami (2004).

\subsection{Data and Model Specification}

Before turning to the data and the empirical model, it might be instructive to consider the Swedish election system and the government's subsidy policy. As of 2009, there are 21 counties in Sweden which cover the entire country. For election to the Swedish parliament, the 29 electoral constituencies are usually coterminous with one of the counties; though the counties of Stockholm, Skåne (containing Malmö, the third largest city by population), and Västra Götaland (containing Gothenburg, the second largest city by population) are divided into smaller electoral constituencies due to their larger populations. Elections are held every fourth year during the sample period, ${ }^{12}$ and determine the makeup of the legislative bodies on the three levels of administrative division in the country. At the highest level, these elections determine the allocation of the 349 seats in the parliament (the Riksdag), that is, the national legislative body of Sweden.

To vote in the parliamentary election, the electoral level considered in the empirical analysis, one must be a Swedish citizen, at least 18 years old, and a resident of Sweden, or alternatively have been a resident of Sweden in the past (thus excluding foreign-born Swedes who have never lived in Sweden).

\footnotetext{
${ }^{12}$ Before 1994, elections were held every third year.
} 
Elections to the 21 county councils (landsting) and 290 municipal assemblies (kommunfullmäktige) are held concurrently with the parliamentary election on the third Sunday of September. Seats in the various legislative bodies are allocated amongst the political parties proportionally.

Regional firm subsidies are distributed by the Swedish government, the Swedish Agency for Economic and Regional Growth (a government agency under the Swedish Ministry of Enterprise, Energy and Communications), and the county administrative boards (länsstyrelserna), which act as the government's regional representatives. Firm subsidies are divided into seven different categories according to their functions, ${ }^{13}$ distributed on an application basis, amounted for the year 2008 to SEK 2.2 billion, or 0.07 percent of GDP, and accumulated to SEK 6.2 billion during 2004-2006. The setup of this grant program gives reason to believe that, besides equity and efficiency concerns, political considerations in the form of re-election motives of the party/parties in power may be a factor in determining how subsidies are distributed across counties.

The sample period is $1994-2006,{ }^{14}$ and all data are from SCB, Statistics Sweden, except data on firm subsidies, which comes from the Swedish Agency for Economic and Regional Growth. A panel data set from Swedish counties is used to estimate regression models of the following forms:

$$
\begin{gathered}
e m p l_{c T}=\alpha_{1}+\alpha_{2} s u b_{c T}+\alpha_{3} z_{1 c T}+\xi_{c}+\xi_{T}+\varepsilon_{1 c T} \\
s u b_{c T}=\beta_{1}+\beta_{2} t_{c T}+\beta_{3} z_{2 c T}+\xi_{c}+\xi_{T}+\varepsilon_{2 c T} \\
e m p l_{c T}=\gamma_{1}+\gamma_{2} t_{c T}+\gamma_{3} z_{3 c T}+\xi_{c}+\xi_{T}+\varepsilon_{3 c T}
\end{gathered}
$$

where $\mathrm{empl}_{c T}$ is the number of employees in county $c$ at time $T$ as a fraction of the number of employees in Sweden at time $T .{ }^{15} s u b_{c T}$ is the total

\footnotetext{
${ }^{13}$ These categories include grants for the development of businesses, regional investment grants, support for commercial service, employment grants, research and development subsidies, transport cost subsidies, and grants to new establishments and entrepreneurship.

${ }^{14}$ This means that four elections took place during the sample period: $1994,1998,2002$, and 2006 .

${ }^{15}$ The theoretical dependent variable of interest in (5.1) and (5.3), $v^{*}$, denotes the number of industrial firms in the North relative to industrial firms located in the South. For data availability reasons, the number firms in a county is proxied by employment. Employment is widely used as a measure of the spatial clustering of economic activity (see
} 
amount of firm subsidies distributed to county $c$ at time $T$, excluding subsidies from the European Regional Development Fund. $e m p l_{c T}$ is scaled up by a factor of 10,000 to avoid too many decimals in the estimates of the regression coefficients, while $s u b_{c T}$ is scaled down by 10,000 to reduce the size of the estimates. $t_{c T}$ denotes the number of votes in county $c$ at time $T$ in the parliamentary election as a fraction of eligible voters in county $c$ at time T. $z_{l c T}, l=1,2,3$, represent vectors of control variables, $\alpha_{1}, \beta_{1}$, and $\gamma_{1}$ are intercepts, $\xi_{c}$ is a county fixed effect, $\xi_{T}$ is a time-specific fixed effect, and $\varepsilon_{l c T}, l=1,2,3$, are error terms capturing all other omitted factors, where $E\left(\varepsilon_{l c T}\right)=0$ for all $c$ and $T$.

Specifically, (5.1) aims to verify premise (1), that more firm subsidies allocated to region $j$ results in more production locating to $j$, which implies that $\alpha_{2}$ is expected to be positive. (5.2) tests the second premise on which Proposition 3 is based, that regions with a higher voter turnout receive more firm subsidies; in other word, (5.2) tests if $\beta_{2}$ is positive. Given the underlying mechanisms of Proposition 3 captured by (5.1) and (5.2), equation (5.3) aims to establish premise (3), the main relationship of interest, that a higher turnout level of region $j$ increases the location of industry in $j$; this amounts to testing if $\gamma_{2}$ is positive. ${ }^{16}$

Two variables are included in the vector $z_{1 c T}$ : the GDP (in SEK) of

for example Ellison and Glaeser [1997], Maurel and Sedillot [1999], and Devereux et al. [2004] for an overview); yet, this empirical proxy does not distinguish between the case when a large number of smaller firms (by employees) are located in county $c$, and when a small number of larger firms are located in $c$. Nevertheless, as argued by Devereux et al. (2004), the latter case may arise endogenously for the same reason as the former, if the agglomeration externalities lead a few firms to internalize the increasing returns to scale in production by acquiring all firms. It should further be noted that this potential measurement error in the dependent variable still gives rise to unbiased estimates of the parameters and their variances, but the estimated variances are larger than in the case where there is no such error.

${ }^{16}$ The subsidies program can be considered as a repeated game: it is a four-year program in which the government distributes money in each of the periods 1994-1998, 1998-2002, and 2002-2006. Voters might hence consider the campaign promises made before an election to be an indication of how the government will act in the future if they win the election, and base their voting decisions upon that. The government then fulfill those promises during its term of office, and firms locate accordingly. In accordance with this game structure, expected voter turnout in the election of, for example, 1994 affects the campaign promises made before the election of 1994. Actual turnout then determines the realization of those promises; that is, the distribution of subsidies during the term of office 1994-1998, which in turn impacts on the location decisions of 1994-1998. 
county $c$ at time $T$ in current prices $\left(g d p_{c T}\right)$, which is supposed to capture the market-access advantage of producing in the county - the coefficient of this variable is expected to be positive; the distance in kilometers between the capital of county $c$ and Stockholm, the capital and largest city of Sweden (the 2009 population amounts to 1,252,020, or 13.4 percent of the total Swedish population), to control for domestic trade costs $\left(\right.$ tcost $\left._{c T}\right)$ - the coefficient estimate of $\operatorname{tcost}_{c T}$ should have a negative sign. ${ }^{17}$ Following Head and Mayer (2003), since it is infeasible to assume that internal distances are zero, it assumed that the internal distance in the County of Stockholm is $2 / 3 \sqrt{m / \pi}$, where $m$ is the area of the county in square kilometers, and $\pi \approx 3.14$. As an alternative measure of transportation costs, and to account for the market size of Gothenburg (the second largest city of Sweden) and Malmö (the third largest city), ${ }^{18}$ their distance to Stockholm was weighted down by a factor proportional to their relative population size: $1-p o p$, where $р о p$ is the average population of the city as a fraction of the average population in Stockholm during the sample period. ${ }^{19}$ However, the inclusion of this alternative distance measure changes the estimations marginally, and the results are therefore not reported in the following analysis.

Three variables are included in the vector $z_{2 c T}: g d p_{c T}$, to control for a potential redistributive component of the Swedish regional policy, i.e., government ambitions to support the development of backward regions, which means that a negative parameter estimate is to be expected; the number of eligible voters of county $c$ at time $T$ in the parliamentary election, to account for the size of the electorate $\left(\right.$ elect $\left._{c T}\right)$, or the number of votes to be gained

\footnotetext{
${ }^{17}$ According to Limão and Venables (2001), distance is a simple and the "most commonly used proxy for transport costs;" they further strongly confirm the importance of geographical measures in determining trade.

${ }^{18}$ The 2009 population of Gothenburg and Malmö is 622,287 and 258,020, respectively.

${ }^{19}$ Malmö is located in the south of Sweden, a short distance from Denmark, which may provide a location advantage following from lower transportation costs in cross-border trade. However, McCallum (1995) finds that Canadian provinces traded over 20 times more with each other than they did with states in the U.S. of the same size and distances; this is the so-called border effect. Subsequent studies of North American, European and OECD trade also found somewhat smaller but still very impressive border effects. Obstfeld and Rogoff (2000) referred to the border effect as one of the "six major puzzles in international macroeconomics." This gives reason to believe that Stockholm - more than twice as large as Gothenburg, and almost five times larger than Malmö - constitutes the core in Swedish inter-regional trade and economic activity; i.e., the region of main reference point when measuring internal distances and domestic transportation costs.
} 
by announcing a specific regional policy - a positive parameter estimate is expected; an index measure of the ideological heterogeneity among voters of county $c$ at time $T\left(h i_{c T}\right)$, to compare the model of Robert-Nicoud and Sbergami (2004) with the prediction of (4.3). Following Campbell (2006), this measure is computed with the formula:

$$
h i_{c T}=100-k_{c T},
$$

where $k_{c T}$ represents the share of the vote taken by the prevailing party in county $c$ at time $T$. Subtracting from 100 means that $h i_{c T}$ increases as a county becomes more politically competitive. According to the prediction of Robert-Nicoud and Sbergami (2004), as the political heterogeneity increases, and the number of swing voters decreases in county $c$ at time $T$, the level of subsidies distributed to $c$ should decrease. The coefficient of $h i_{c T}$ in (5.2) is therefore expected to be negative if their model is correct. However, as pointed out in the Introduction, the number of swing voters is a latent variable and cannot be observed. The validity of the variable estimation procedure requires, for example, that voters' ideological preferences are symmetric and single peaked; therefore, $h i_{c T}$ is an approximation of the theoretical variable and measurement errors cannot be ruled out.

Four variables are included in the vector $z_{3 c T}: g d p_{c T}$, to capture the market-access advantage of county $c$ (theory predicts a positive parameter estimate); $\operatorname{tcost}_{c T}$, to take into account domestic trade costs (a negative coefficient on $\operatorname{tcost}_{c T}$ is expected); elect $_{c T}$, thereby controlling for the potential number of votes to be gained (the estimate of elect ${ }_{c T}$ should have a positive sign); $h i_{c T}$, to compare the empirical relevance of Proposition 3 with the model of Robert-Nicoud and Sbergami (2004), which predicts that the coefficient on $h i_{c T}$ is negative - as the political heterogeneity increases, and the number of swing voter decreases, the location of production, or the number of employees, should decrease via less regional transfers allocated to county c.

Table 1 contains descriptive statistics for the variables. 
Table 1: Descriptive statistics

\begin{tabular}{|c|c|c|c|c|}
\hline Variables & Mean & Standard deviation & Minimum & Maximum \\
\hline Employment share: $e m p l_{c T}$ & 0.0476 & 0.0566 & 0.0062 & 0.2472 \\
\hline Turnout: $t_{c T}$ & 82.86 & 3.06 & 77.65 & 88.30 \\
\hline Subsidies: $s u b_{c T}$ & $42,400,000$ & $46,500,000$ & 130,000 & $209,000,000$ \\
\hline GDP: $g d p_{c T}$ & 106,863 & 145,145 & 9,170 & 837,041 \\
\hline Transportation cost: tcost $_{c T}$ & 292 & 174 & 30 & 726 \\
\hline Eligible voters: elect $_{c T}$ & 263,367 & 195,354 & 43,795 & 804,300 \\
\hline Ideological heterogeneity: $h i_{c T}$ & 58.54 & 8.16 & 39.42 & 86.80 \\
\hline Local rainfall: $\operatorname{rain}_{c T}$ & 67.59 & 14.01 & 50.10 & 113.40 \\
\hline
\end{tabular}

Notes: empl $l_{c T}$ and $s u b_{c T}$ are not scaled in Table 1. $\operatorname{rain}_{c T}$ is an instrumental variable for $t_{c T}$, applied in Subsection 5.3.

\subsection{Results}

Table 2 reports the OLS estimation results of (5.1) and (5.2). As shown in the first column, and predicted by (2.17), the coefficient on $s u b_{c T}, \alpha_{2}$, is significantly positive (though at the 10 percent level): adjusting for the scaling of $e m p l_{c T}$ and $s u b_{c T}$, an increase in firm subsidies by SEK 1 billion to county $c$ increases the number of employees in $c$ as a fraction of the number of employees in Sweden by 0.005 units. The positive and significant coefficient on $g d p_{c T}$ confirms the market-access advantage of producing in larger counties, while $\operatorname{tcost}_{c T}$ is significantly negative, implying a location disadvantage of distant counties due to higher transportation costs in inter-regional trade. After adjusting for the scaling, and standardizing the coefficients to compare the relative impact in terms of standard deviation changes, the estimated employment effect of subsidies is economically less significant than GDP and transport costs: a one standard deviation change in firm subsidies leads to a 0.004 standard deviation change in the dependent variable, compared to 0.046 and 0.027 for GDP and transportation costs, respectively.

As predicted by (4.3), and shown in the second column, $\beta_{2}$ is positive; that is, turnout is a significant positive predictor of the distribution of firm subsidies across counties. Taking into account the scaling of $s u b_{c T}$, increasing turnout by one percentage point increases the total amount of subsidies distributed to county $c$ by SEK 1.1 million. $g d p_{c T}$ is, as to be expected, significantly negative, reflecting a redistributive Swedish regional policy directed towards the support of backward counties. The negative coefficient on $h i_{c T}$ confirms the prediction of Robert-Nicoud and Sbergami (2004), that 
fewer swing voters of county $c$ results in less firm subsidies allocated to $c$. To compare their framework with the turnout perspective taken in this paper, a one standard deviation change in $t_{c T}$ is associated with a 0.073 standard deviation change in the dependent variable, while the corresponding subsidy effect from $h i_{c T}$ is 0.072. By comparing standardized coefficients, it follows that $t_{c T}$ and $h i_{c T}$ are economically less significant than $g d p_{c T}$ and elect $t_{c T}$ as determinants of the distribution of firm subsidies: 0.073 and 0.072 compared to 0.27 and 1.07, respectively.

Table 2: OLS estimations of (5.1) and $(5.2)$

\begin{tabular}{|c|c|c|}
\hline & $e m p l_{c T}$ & $s u b_{c T}$ \\
\hline$t_{c T}$ & & $\begin{array}{c}111^{* *} \\
(49)\end{array}$ \\
\hline$s u b_{c T}$ & $\begin{array}{c}0.0005^{*} \\
(0.0003)\end{array}$ & \\
\hline$g d p_{c T}$ & $\begin{array}{c}0.000178^{* * *} \\
(0.0000643)\end{array}$ & $\begin{array}{r}-0.0087^{* *} \\
(0.00346)\end{array}$ \\
\hline$t \cos t_{c T}$ & $\begin{array}{c}-0.0866^{* * *} \\
(0.0132)\end{array}$ & \\
\hline $\operatorname{elect}_{c T}$ & & $\begin{array}{c}0.0256^{* *} \\
(0.0124)\end{array}$ \\
\hline$h i_{c T}$ & & $\begin{array}{c}-44^{* * *} \\
(15.6)\end{array}$ \\
\hline$N$ & 273 & 273 \\
\hline$R^{2}$ & 0.2 & 0.12 \\
\hline
\end{tabular}

Table 3 reports the estimation results of (5.3). Most importantly, the estimated coefficient on $t_{c T}, \gamma_{2}$, is highly significant and positive in all specifications, providing support for Proposition 3, that there exists a positive relation between voter turnout in region $j$ and the location of production in $j$. Furthermore, the inclusion of different controls has little effect on the estimates of turnout on employment. Adjusting for the scaled dependent variable, an increase in turnout by one percentage point increases the number of employees in county $c$ as a fraction of the number of employees in Sweden 
by $0.00008-0.0001$ units. $g d p_{c T}$ is significantly positive, which gives support to the notion of a market-access advantage of locations close to relatively larger markets. The significantly negative coefficient on tcost $_{c T}$ confirms a location disadvantage of rural areas in inter-regional trade. The insignificant coefficient on elect $_{c T}$ might reflect a high multicollinearity between turnout and the number of eligible voters, i.e., the size of the electorate. The significant and negative coefficient on $h i_{c T}$ lends support to the prediction of Robert-Nicoud and Sbergami (2004). As a model comparison, a one standard deviation change in $t_{c T}$ leads to a 0.0043-0.0062 standard deviation change in $\mathrm{empl}_{c T}$, while the corresponding standardized coefficient of $h i_{c T}$ is 0.0044. The effects of GDP and transportation costs are 0.051-0.077 and $0.016-0.028$, respectively.

Since the dependent variable is scaled by a factor of 10,000 , the coefficient of, for example, GDP in Table 3 column (4), implies that an increase in GDP of county $c$ by SEK 1 billion increases the number of employees in $c$ as a fraction of the number of employees in Sweden by 30 units. Crafts and Klein (2009) estimate that an increase in the market potential, measured by the interaction of distance-weighted GDP and industry sale, by USD 1 billion, increases the share of manufacturing labor force on the U.S. state level by 300,000 units - a 10,000-fold difference in estimates. Although their study is not comparable with the current one, this indicates that the estimated coefficients in Table 3 may be relatively small in magnitude, some possibly biased downward. 
Table 3: OLS estimations of equation (5.3)

\begin{tabular}{lcccc}
\hline \hline & 1 & 2 & 3 & 4 \\
\hline$t_{c T}$ & $1.042^{* * *}$ & $1.033^{* * *}$ & $1.154^{* * *}$ & $0.791^{* * *}$ \\
& $(0.298)$ & $(0.298)$ & $(0.298)$ & $(0.296)$ \\
$g d p_{c T}$ & $0.0002^{* * *}$ & $0.0002^{* * *}$ & $0.0003^{* * *}$ & $0.0003^{* * *}$ \\
& $(0.00007)$ & $(0.00007)$ & $(0.00007)$ & $(0.00007)$ \\
tcost $_{c T}$ & & $-0.083^{* * *}$ & $-0.091^{* * *}$ & $-0.052^{* * *}$ \\
& & $(0.009)$ & $(0.011)$ & $(0.014)$ \\
elect $_{c T}$ & & & -0.0003 & -0.0003 \\
& & & $(0.0002)$ & $(0.0002)$ \\
$h i_{c T}$ & & & & $-0.305^{* * *}$ \\
& & & & $(0.082)$ \\
$N$ & 273 & 273 & 273 & 273 \\
$R^{2}$ & 0.95 & 0.78 & 0.03 & 0.02 \\
\hline \hline
\end{tabular}

Notes: The dependent variable $\left(e m p l_{c T}\right)$ is the number of employees in county $c$ at time $T$ as a fraction of the number of employees in Sweden at time $T$. Robust standard errors clustered by county in parentheses with $*, * *$, and $* * *$ denoting significance at the 10,5 , and 1 percent levels, respectively. County fixed effects and time-specific fixed effects are included in all regressions.

\subsection{Instrumental Variable Estimation}

By combining (3.20), $\omega \equiv \frac{V_{S}}{V_{N}},(2.18)$ and (2.19) it follows that the distribution of production affects the relative turnout level; that is, turnout is endogenous to the location of industry, and the estimation of causal effects requires exogenous sources of variation. To account for this simultaneity, an instrumental variable strategy is implemented to re-estimate (5.3).

Earlier studies validate the long-held belief that bad weather is correlated with levels of voter turnout, i.e., rainfall is expected to suppress voter turnout. For example, prior work by Gomez et al. (2007), Gomez and Hansford (2008), Horiuchi and Saito (2007), Knack (1994), and Merrifield (1993), suggest that a potential instrument for turnout might be weather or specifically, local rainfall, the operationalization of bad weather.

To account for any systematic effect of weather on turnout, the rainfall normal value of an average day in the election month, September, during 1961-1990 in the capital of county $c$ (or measured from the nearest weather station within the county borders) is used as an instrument for the voter turnout of $c$. Rainfall (denoted $\operatorname{rain}_{c T}$ in Table 1) is measured in millimeters, and collected from SMHI, the Swedish Meteorological and Hydrological 
Institute, a government agency under the Swedish Ministry of the Environment.

The exclusion restriction implied by the instrumental variable strategy is that, conditional on the controls included in the regression, local rainfall has no effect on the distribution of production, other than its effect through voter turnout. This restriction is plausible for non-extreme systematic regional deviations in rainfall from the national average that might affect the location of industry. To test the restriction formally, $\operatorname{rain}_{c T}$ is added as an exogenous regressor. If rainfall has a direct effect on $e m p l_{c T}$, it is expected to be negative and significant. An OLS regression of $e m p l_{c T}$ on $\operatorname{rain}_{c T}$ shows that this variable indeed is insignificant, thus the impact of rainfall likely works through its effect on turnout. Moreover, local rainfall is certainly exogenous to the location of production. These properties indicate that rainfall in Swedish counties may serve as a suitable instrument for turnout. To determine whether this instrument has sufficient explanatory power, an $F$-test of the hypothesis that the instrument does not enter the first stage regression of (5.3) is performed.

Table 4 reports the results of the IV regression of (5.3). The F-test is significant, rejecting the null hypothesis that the instrument does not enter the first stage regression. As in the OLS models, the coefficient on $t_{c T}$ is significantly positive: adjusting for the scaled dependent variable, a one percentage point increase in voter turnout increases the number of employees in county $c$ as a fraction of the number of employees in Sweden by 0.012 units. However, there is a considerable difference in the magnitude of the point estimates, indicating that the OLS estimators may be severely biased downward. Arguably, this seems likely given that the coefficients in Table 3 are comparatively small. The downward bias can be rationalized if the product of the OLS elasticity of $e m p l_{c T}$ with respect to $t_{c T}$, and that of $t_{c T}$ with respect to $\mathrm{empl}_{c T}$, is larger than one. ${ }^{20}$ By Table $3, \gamma_{2}>1$ (0.791 in column (4)), thus the OLS estimator is biased downward if the elasticity of $t_{c T}$ with respect to $\mathrm{empl}_{c T}$ is larger than one; that is, if turnout in county $c$ increases more than proportionate to the location of production, or employment, in $c$.

\footnotetext{
${ }^{20}$ Define $e m p l_{c T}=\gamma_{1}+\gamma_{2} t_{c T}+\gamma_{3} z_{I c T}+\varepsilon_{c T}$ and $t_{c T}=\delta_{1}+\delta_{2} e m p l_{c T}+\delta_{3} z_{I I c T}+\epsilon_{c T}$, where $z_{I c T}$ and $z_{I I c T}$ are vectors of exogenous variables. The OLS estimator, $\gamma_{2}$, is biased downward (upward) when $t_{c T}$ and $\varepsilon_{c T}$ are negatively (positively) correlated. With respect to this correlation, the reduced form equation for $t_{c T}$ includes a term for $\varepsilon_{c T}$ : $t_{c T}=\frac{\delta_{2}}{1-\delta_{2} \gamma_{2}} \varepsilon_{c T} \ldots$ In terms of the theoretical model, $\delta_{2}>0$ and $\gamma_{2}>0$. Hence, the OLS estimate of $\gamma_{2}$ is biased downward if $\delta_{2} \gamma_{2}>1$.
} 
This is a valid assumption if a higher share of industry in county $c$ results in a large inflow of labor, i.e., voters, from neighboring counties.

As to be expected, $g d p_{c T}$ is significant and positive, while $\operatorname{tcost}_{c T}$ loses its significance and $h i_{c T}$ changes sign. It follows that a one standard deviation change in turnout leads to a 2.92 standard deviation change in $\mathrm{empl}_{c T}$, compared to 0.92 for $g d p_{c T}$. The significantly positive coefficient on $h i_{c T}$ contradicts the prediction of Robert-Nicoud and Sbergami (2004), that industry locates in politically homogenous regions where a higher density of swing voters attracts more regional transfers. The positive coefficient could, however, be consistent with the view that the Swedish Social Democratic Party had crafted an advantage in the parliamentary elections during the sample period; i.e., they could win without engaging in political competition for the support of swing voters. ${ }^{21}$ Shaw (2008) argues that this was the case in the U.S. presidential elections of 1968, 1972, and 1976; although there were more swing voters in these elections, the distribution of party-line voting was less balanced - one could win without carrying swing voters. Such an interpretation implies that a higher political homogeneity in county $c$ may decrease the distribution of costly regional funds to $c$, which in turn decreases the economic benefit of locating production to this county.

It should be noted though, as pointed out in the Introduction, that the number of swing voters, supposed to be captured by the ideological heterogeneity index in (5.4), is a latent variable inferred from assumptions of symmetric and single peaked ideological preferences; therefore, $h i_{c T}$ is a proxy, and potential measurement errors cannot be ruled out.

A Hausman test for endogeneity of voter turnout, the null hypothesis being that it is exogenous, is rejected. The implication is that the OLS estimates are biased and inconsistent.

\footnotetext{
${ }^{21}$ The Swedish Social Democratic Party was in power during the sample period, 19942006.
} 
Table 4: IV estimation of equation (5.3)

\begin{tabular}{lccccc}
\hline \hline & $t_{c T}$ & $g d p_{c T}$ & tcost $_{c T}$ & elect $_{c T}$ & \multicolumn{1}{c}{$h i_{c T}$} \\
\hline & $119.7^{* *}$ & $0.0036^{* * *}$ & 0.076 & 0.00007 & $15.03^{*}$ \\
& $(61)$ & $(0.0002)$ & $(0.11)$ & $(0.00011)$ & $(9.048)$ \\
$N$ & 273 & & & & \\
$R^{2}$ & 0.68 & & & & \\
$F$ & $9.05^{* * *}$ & & & & \\
$\chi^{2}$ & $95.9^{* * *}$ & & & & \\
\hline \hline
\end{tabular}

Notes: The dependent variable $\left(e m p l_{c T}\right)$ is the number of employees in county $c$ at time $T$ as a fraction of the number of employees in Sweden at time $T$. Robust standard errors clustered by county in parentheses with $*, * *$, and $* * *$ denoting significance at the 10, 5, and 1 percent levels, respectively. County fixed effects and time-specific fixed effects are included in the regression. $F$ is the test statistic of the hypothesis that the instrument does not enter the first stage regression. $\chi^{2}$ is the Hausman test statistic for endogeneity, a test of the significance of differences between the OLS estimates in column (4), Table 3, and the IV estimation.

\section{Conclusions}

The results derived in Robert-Nicoud and Sbergami (2004) rest on the assumption of asymmetric regional ideological preferences: the social and economic activities are more heterogeneous in the urban region, which implies a relatively higher density of swing voters in the rural region. This makes the political candidates adjust their policy positions to the preferences of the electorate in the smaller region. However, Campbell (2006) argues that this driving assumption is not supported by data; the ideological heterogeneity is not determined by the percentage of a community's population that is urban.

It is on the other hand empirically well-confirmed that voter groups with a higher turnout are more likely to be represented in the policy-making process. Recognizing the view that regions exert political influence by their propensity to vote, this paper has analyzed how the endogenous determination of the distribution of regional subsidies affects the equilibrium location of manufacturing production. The theoretical model solves for the location of industry as a function of an observable political variable: the regional voter turnout level. In doing so, the properties of the location equilibrium can be subjected to straightforward empirical testing.

It has been shown in this paper that economic strength with relative factor abundance and a large industry sector will give rise to less net subsidies 
in the political economy equilibrium. The reason is that voters in the South reward policy with a relatively higher turnout. This reverses the agglomeration process, and as trade is increasingly liberalized, the economy features a reversed core-periphery equilibrium. The findings presented qualitatively resemble those of Robert-Nicoud and Sbergami (2004); but as argued in the current paper, their reversed core-periphery equilibrium is not subgame perfect in the sense that firms must internalize the expected subsidy-included relative return to capital when relocation decisions are made.

Empirical results confirm the view that firms locate at higher rates to regions with higher turnout. 


\section{References}

Baldwin, R., Forslid, R., Martin, P., Ottaviano, G. and Robert-Nicoud, F. (2003) Economic Geography and Public Policy (New Jersey: Princeton University Press).

Button, J. W. (1989) Blacks and Social Change: Impact of the Civil Rights Movement in Southern Communities (New Jersey: Princeton University Press).

Cadot, O., Röller, L. H. and Stephan, A. (2006) "Contribution to Productivity or Pork Barrel? The Two Faces of Infrastructure Investment", Journal of Public Economics, vol. 90, pp. 1133-1153.

Campbell, D. E. (2006) Why We Vote (New Jersey: Princeton University Press).

Crafts, N. and Klein, A. (2009) "Making Sense of the Manufacturing Belt: Determinants of U.S. Industrial Location, 1880-1920" (University of Warwick: Mimeo).

Devereux, M. P., Griffith, R. and Simpson, H. (2004) "The Geographic Distribution of Production Activity in Britain", Regional Science and Urban Economics, vol. 34, pp. 533-564.

Dixit, A. and Stiglitz, J. (1977) "Monopolistic Competition and the Optimal Product Diversity", American Economic Review, vol. 67, pp. 297-308.

Ellison, G. and Glaeser, E. (1997) "Geographic Concentration in U.S. Manufacturing Industries: A Dartboard Approach", Journal of Political Economy, vol. 105, pp. 889-927.

Feddersen, T. and Sandroni, A. (2006) "A Theory of Participation in Elections", American Economic Review, vol. 96, pp. 1271-1282.

Flam, H. and Helpman, E. (1987) "Industrial Policy under Monopolistic Competition", Journal of International Economics, vol. 22, pp. 79-102. 
Gomez, B. T., Hansford, T. G. and Krause, G. A. (2007) "The Republicans Should Pray for Rain: Weather, Turnout, and Voting in U.S. Presidential Elections", Journal of Politics, vol. 69, pp. 649-663.

Gomez, B. T. and Hansford, T. G. (2008) "Who Benefits from High Turnout?" (Florida State University: Mimeo).

Head, K. and Mayer, T. (2003) "The Empirics of Agglomeration and Trade" (CEPR: Mimeo).

Hicks, A. M. and Swank, D. H. (1992) "Politics, Institutions, and Welfare Spending in Industrialized Democracies, 1960-82", American Political Science Review, vol. 86, pp. 658-674.

Hanson, G. (2005) "Market Potential, Increasing Returns and Geographic Concentration", Journal of International Economics, vol. 67, pp. 1-24.

Harsanyi, J. C. (1977) "Morality and the Theory of Rational Behavior", Social Research, vol. 44, pp. 623-656.

Harsanyi, J. C. (1980) "Rule Utilitarianism, Rights, Obligations and the Theory of Rational Behavior", Theory and Decision, vol. 12, pp. 115-133.

Harsanyi, J. C. (1992) "Game and Decision Theoretic Models in Ethics", in Aumann, R. and Hart, S. (eds.) Handbook of Game Theory with Economic Application (Amsterdam: Elsevier Science, North-Holland), pp. 669-707.

Hill, K. Q. and Leighley, R. E. (1992) "The Policy Consequences of Class Bias in State Electorates", American Journal of Political Science, vol. 36, pp. 351-365.

Homburg, S. (1997) "Ursachen und Wirkungen eines Zwischenstaatlichen Finanzausgleichs", in Oberhauser, A. (ed.) Fiskalföderalismus in Europa (Berlin: Duncker and Humblot).

Horiuchi, Y. and Saito, J. (2007) "Rain, Election, and Money: The Impact of Voter Turnout on Distributive Policy Outcomes" (Australian National University: Mimeo). 
Keech, W. R. (1968) The Impact of Negro Voting; the Role of the Vote in the Quest for Equality (Chicago: Rand McNally).

Knack, S. (1994) "Does Rain Help the Republicans? Theory and Evidence on Turnout and the Vote", Public Choice, vol. 79, pp. 187-209.

Krugman, P. (1980) "Increasing Returns and Economic Geography", American Economic Review, vol. 70, pp. 950-959.

Krugman, P. (1991) "Scale Economies, Product Differentiation and Pattern of Trade", Journal of Political Economy, vol. 99, pp. 483-499.

Limão, N. and Venables, A. J. (2001) "Infrastructure, Geographical Disadvantage, Transport Costs, and Trade", World Bank Economic Review, vol. 15, pp. 451-481.

Martin, P. S. (2003) "Voting's Rewards: Voter Turnout, Attentive Publics and Congressional Allocation of Federal Money", American Journal of Political Science, vol. 47, pp. 110-127.

Martin, P. and Rogers, C. A. (1995) "Industrial Location and Public Infrastructure", Journal of International Economics, vol. 39, pp. 335-351.

Maurel, F. and Sedillot, B. (1999) "A Measure of the Geographic Concentration in French Manufacturing Industries", Regional Science and Urban Economics, vol. 29, pp. 575-604.

McCallum, J. (1995) "National Borders Matter: Canada-U.S. Regional Trade Patterns", American Economic Review, vol. 85, pp. 615-623.

Merrifield, J. (1993) "The Institutional and Political Factors that Influence Voter Turnout", Public Choice, vol. 77, pp. 657-669.

Obstfeld, M. and Rogoff, K. (2000) "The Six Major Puzzles in International Macroeconomics: Is There a Common Cause?"National Bureau of Economic Research Paper 7777. 
Robert-Nicoud, F. and Sbergami, F. (2004) "Home-Market vs. Vote-Market Effect: Location Equilibrium in a Probabilistic Voting Model", European Economic Review, vol. 48, pp. 155-179.

Shaw, D. R. (2008) "Swing Voting and U.S. Presidential Elections", in Mayer, W. G. (ed.) The Swing Voter in American Politics (Washington, D.C.: Brookings Institution Press).

Strömberg, D. (2004) "Radio's Impact on Public Spending", Quarterly Journal of Economics, vol. 119, pp. 189-221.

Wiberg, M. (2010) "Location Equilibrium with Endogenous Rent Seeking", Journal of Economic Geography, vol. 9, pp. 869-887. 


\section{A Appendix}

\section{A.1 Derivation of (2.18) and (2.19)}

The indirect utility function of a representative agent in region $j$ with preferences given by (2.2) is: $\frac{E_{j}}{\left(\int_{k=0}^{n_{W}} p_{j k}{ }^{1-\sigma} d k\right)^{\frac{-\mu}{\sigma-1}}}$. Using $w=1, \rho_{W} K_{W}=\frac{x_{W} K_{W}}{\sigma}+$ $T L_{W}$ and normalizing $L_{W}$ to unity without loss of generality to obtain the representative individual's net earnings: $E_{j}=1+\rho_{W} K_{W}-T=1+\frac{x_{W} K_{W}}{\sigma}$. $\frac{x_{W} K_{W}}{\sigma}=\frac{x_{N} n_{N}+x_{S} n_{S}}{\sigma}=\pi_{N} n_{N}+\pi_{S} n_{S}$. Substituting (2.10) into (2.11) and (2.12) gives: $\pi_{N} n_{N}+\pi_{S} n_{S}=\frac{a s_{E_{N}}\left(n_{N}+n_{S} \phi\right)}{\left(n_{N}+n_{S} \phi\right)}+\frac{a\left(1-s_{E_{N}}\right)\left(n_{N} \phi+n_{S}\right)}{\left(n_{N} \phi+n_{S}\right)}=a$, which yields:

$$
E_{j}=1+a .
$$

Solving for the price index prevailing in the North and the South, respectively:

$$
\left(\int_{k=0}^{n_{W}} p_{N k}{ }^{1-\sigma} d k\right)^{\frac{-\mu}{\sigma-1}}=\left(n_{N}+n_{S} \phi\right)^{\frac{-\mu}{\sigma-1}}=\left(s_{N}+\left(1-s_{N}\right) \phi\right)^{\frac{-\mu}{\sigma-1}}=\left(\frac{\phi+v}{1+v}\right)^{\frac{-\mu}{\sigma-1}}
$$

and

$$
\left(\int_{k=0}^{n_{W}} p_{S k}^{1-\sigma} d k\right)^{\frac{-\mu}{\sigma-1}}=\left(n_{N} \phi+n_{S}\right)^{\frac{-\mu}{\sigma-1}}=\left(s_{N} \phi+\left(1-s_{N}\right)\right)^{\frac{-\mu}{\sigma-1}}=\left(\frac{1+v \phi}{1+v}\right)^{\frac{-\mu}{\sigma-1}},
$$

where $s_{N} \equiv \frac{n_{N}}{n_{W}}$ and $1-s_{N} \equiv \frac{n_{W}-n_{N}}{n_{W}}=\frac{n_{S}}{n_{W}}$. Normalizing $n_{W}$ to unity, noting that $s_{N}=\frac{v}{1+v} \in(0,1)$ for an interior solution, gives (A.2) and (A.3). Substituting (A.1), (A.2) and (A.3) into the indirect utility function and taking the logarithm of the resulting expression to obtain (2.18) and (2.19).

A.2 Proof of $\frac{\partial V_{S}}{\partial \phi}>0$ if $s_{N}>\frac{\partial s_{N}}{\partial \phi}(1-\phi)$ and $\frac{\partial V_{N}}{\partial \phi}<\frac{\partial V_{S}}{\partial \phi}$ if

$$
s_{N}>\frac{1+\frac{\partial s_{N}}{\partial \phi}\left(1-\phi^{2}\right)}{2}
$$

Rewrite (2.18) and (2.19):

$$
V_{N}(\phi, \theta)=\ln (1+a)+\frac{\mu}{\sigma-1} \ln \left(s_{N}+\left(1-s_{N}\right) \phi\right),
$$


and

$$
V_{S}(\phi, \theta)=\ln (1+a)+\frac{\mu}{\sigma-1} \ln \left(s_{N} \phi+\left(1-s_{N}\right)\right) .
$$

Taking the derivative of (A.4) with respect to $\phi$ yields:

$$
\frac{\partial V_{N}}{\partial \phi}=\frac{\mu}{\sigma-1} \frac{\frac{\partial s_{N}}{\partial \phi}(1-\phi)+1-s_{N}}{s_{N}+\left(1-s_{N}\right) \phi}>0,
$$

if $\frac{\partial s_{N}}{\partial \phi}>0$, and manufacturing production takes place in both regions, that is, if $s_{N} \in(0,1)$. Taking the derivative of (A.5) with respect to $\phi$ gives:

$$
\frac{\partial V_{S}}{\partial \phi}=\frac{\mu}{\sigma-1} \frac{s_{N}-\frac{\partial s_{N}}{\partial \phi}(1-\phi)}{s_{N} \phi+\left(1-s_{N}\right)}>0,
$$

if $s_{N}>\frac{\partial s_{N}}{\partial \phi}(1-\phi)$, and manufacturing production takes place in both regions.

Using (A.6) and (A.7) it is straightforward to show that $\frac{\partial V_{N}}{\partial \phi}<\frac{\partial V_{S}}{\partial \phi}$ if $\frac{s_{N}-\frac{\partial s_{N}}{\partial \phi}(1-\phi)}{s_{N} \phi+\left(1-s_{N}\right)}>\frac{\frac{\partial s_{N}}{\partial \phi}(1-\phi)+1-s_{N}}{s_{N}+\left(1-s_{N}\right) \phi}$, i.e., if $s_{N}>\frac{1+\frac{\partial s_{N}}{\partial \phi}\left(1-\phi^{2}\right)}{2}$. Noting that $1-s_{N}=$ $s_{S}$, this implies that $\frac{\partial V_{N}}{\partial \phi}<\frac{\partial V_{S}}{\partial \phi}$ if $s_{S}<\frac{1-\frac{\partial s_{N}}{\partial \phi}\left(1-\phi^{2}\right)}{2}$. QED.

\section{A.3 Proof of $\frac{\partial t}{\partial \phi}>0$}

Equation (3.20) reproduced:

$$
t=f\left(V_{N}\left(\phi, s_{N}(\phi, \lambda, \theta)\right), V_{S}\left(\phi, s_{N}(\phi, \lambda, \theta)\right), \lambda\right),
$$

where $s_{N}=\frac{v}{1+v}$. Totally differentiating (A.8) with respect to $\phi$ yields:

$$
\frac{\partial t}{\partial \phi}=\frac{\partial f}{\partial V_{N}} \frac{\partial V_{N}}{\partial \phi}+\frac{\partial f}{\partial V_{N}} \frac{\partial V_{N}}{\partial s_{N}} \frac{\partial s_{N}}{\partial \phi}+\frac{\partial f}{\partial V_{S}} \frac{\partial V_{S}}{\partial \phi}+\frac{\partial f}{\partial V_{S}} \frac{\partial V_{S}}{\partial s_{N}} \frac{\partial s_{N}}{\partial \phi},
$$

where $\frac{\partial f}{\partial V_{N}}<0, \frac{\partial V_{N}}{\partial \phi}>0, \frac{\partial V_{N}}{\partial s_{N}}>0, \frac{\partial s_{N}}{\partial \phi} \geq 0$ (by assumption), $\frac{\partial f}{\partial V_{S}}>0$, $\frac{\partial V_{S}}{\partial \phi}>0$ if $s_{N}>\frac{\partial s_{N}}{\partial \phi}(1-\phi)$, and $\frac{\partial V_{S}}{\partial s_{N}}<0$. It follows from (A.9) that $\frac{\partial t}{\partial \phi}>0$ if:

$$
\frac{\partial f}{\partial V_{S}}\left(\frac{\partial V_{S}}{\partial \phi}+\frac{\partial V_{S}}{\partial s_{N}} \frac{\partial s_{N}}{\partial \phi}\right)>-\frac{\partial f}{\partial V_{N}}\left(\frac{\partial V_{N}}{\partial \phi}+\frac{\partial V_{N}}{\partial s_{N}} \frac{\partial s_{N}}{\partial \phi}\right)
$$


where $\frac{\partial V_{N}}{\partial \phi}+\frac{\partial V_{N}}{\partial s_{N}} \frac{\partial s_{N}}{\partial \phi}>0$, that is, if:

$$
\frac{\frac{\partial V_{S}}{\partial \phi}+\frac{\partial V_{S}}{\partial s_{N}} \frac{\partial s_{N}}{\partial \phi}}{\frac{\partial V_{N}}{\partial \phi}+\frac{\partial V_{N}}{\partial s_{N}} \frac{\partial s_{N}}{\partial \phi}}>-\frac{\frac{\partial f}{\partial V_{N}}}{\frac{\partial f}{\partial V_{S}}}=\omega<1
$$

Hence, $\frac{\partial t}{\partial \phi}>0$ if:

$$
\frac{\partial V_{S}}{\partial \phi}+\frac{\partial V_{S}}{\partial s_{N}} \frac{\partial s_{N}}{\partial \phi}>\frac{\partial V_{N}}{\partial \phi}+\frac{\partial V_{N}}{\partial s_{N}} \frac{\partial s_{N}}{\partial \phi}
$$

That is, if:

$$
\frac{\partial V_{S}}{\partial \phi}-\frac{\partial V_{N}}{\partial \phi}+\frac{\partial s_{N}}{\partial \phi}\left(\frac{\partial V_{S}}{\partial s_{N}}-\frac{\partial V_{N}}{\partial s_{N}}\right)>0
$$

where $\frac{\partial V_{S}}{\partial \phi}-\frac{\partial V_{N}}{\partial \phi}>0$ if $s_{S}<\frac{1-\frac{\partial s_{N}}{\partial \phi}\left(1-\phi^{2}\right)}{2}$, as shown in Appendix A.2. This implies that $\frac{\partial t}{\partial \phi}>0$ if:

$$
\frac{\partial s_{N}}{\partial \phi}\left(\frac{\partial V_{S}}{\partial s_{N}}-\frac{\partial V_{N}}{\partial s_{N}}\right)>0
$$

Using $(2.15)$ in $s_{N}=\frac{v}{1+v}$ to obtain:

$$
\frac{\partial V_{S}}{\partial s_{N}}-\frac{\partial V_{N}}{\partial s_{N}}=\frac{\mu(1-\phi)\left(\phi-\theta+s_{E_{N}}(\theta-1)(1+\phi)\right)^{2}}{s_{E_{N}}\left(1-s_{E_{N}}\right)(\sigma-1)(\theta-\phi)(\theta \phi-1)}>0
$$

if $\phi>\frac{1}{\theta}$, since $\theta>1$ by Appendix A.6. Thus $\frac{\partial t}{\partial \phi}>0$ if $s_{S}<\frac{1-\frac{\partial s_{N}}{\partial \phi}\left(1-\phi^{2}\right)}{2}$ and $\phi>\frac{1}{\theta}$.

Further, note that:

$$
\frac{\partial V_{S}}{\partial \phi}-\frac{\partial V_{N}}{\partial \phi}+\frac{\partial s_{N}}{\partial \phi}\left(\frac{\partial V_{S}}{\partial s_{N}}-\frac{\partial V_{N}}{\partial s_{N}}\right)=-\frac{\mu\left(\theta^{2}-1\right)}{(\sigma-1)(\theta-\phi)(\theta \phi-1)}>0
$$

if $\phi<\frac{1}{\theta}$, since $\theta>1$ by Appendix A.6. Then clearly, $\frac{\partial t}{\partial \phi}>0 \forall \frac{\partial s_{N}}{\partial \phi}$ if $\phi<\frac{1}{\theta}$. QED.

Consequently, $\frac{\partial t}{\partial \phi}>0$ if $\phi>\frac{1}{\theta}$ and $s_{S}<\frac{1-\frac{\partial s_{N}}{\partial \phi}\left(1-\phi^{2}\right)}{2}$, and if $\phi<\frac{1}{\theta} \forall \frac{\partial s_{N}}{\partial \phi}$. 


\section{A.4 Derivation of (3.22)}

Consider the case where firms in the North are subsidized, where the division of manufacturing activity adjusts until $\frac{\pi_{N}}{\pi_{S}}=\frac{1}{1+z_{N}}$. Solving this equilibrium condition for $v$, using the resulting expression in (2.18) and (2.19), substituting (2.18) and (2.19) into (3.20), then taking the first order condition of (3.21) to obtain:

$$
\frac{\partial P}{\partial z_{N}}=\frac{\partial \bar{F}}{\partial t} \frac{\partial t}{\partial V_{N}} \frac{\partial V_{N}}{\partial v} \frac{\partial v}{\partial z_{N}}+\frac{\partial \bar{F}}{\partial t} \frac{\partial t}{\partial V_{S}} \frac{\partial V_{S}}{\partial v} \frac{\partial v}{\partial z_{N}}=0
$$

which simplifies to:

$$
\frac{\partial P}{\partial z_{N}}=\frac{1}{V_{N}} \frac{\partial V_{N}}{\partial v}-\frac{1}{V_{S}} \frac{\partial V_{S}}{\partial v}=0 .
$$

Solving (A.18) for $z_{N}$ implies that:

$$
1+z_{N}^{*}=\frac{\lambda^{2} \phi-t^{2}}{\lambda^{2}-t^{2} \phi}
$$

Suppose instead that production in the South is subsidized, where the division of firms adjusts until $\frac{\pi_{N}}{\pi_{S}}=1+z_{S}$. Solving this location condition for $v$, using the resulting expression in (2.18) and (2.19), substituting (2.18) and (2.19) into (3.20), then taking the first order condition of (3.21) yields:

$$
1+z_{S}^{*}=\frac{\lambda^{2}-t^{2} \phi}{\lambda^{2} \phi-t^{2}}
$$

(A.19) and (A.20) gives (3.22):

$$
\theta^{*}=\frac{1+z_{S}^{*}}{1+z_{N}^{*}}=\left(\frac{\lambda^{2}-t^{2} \phi}{\lambda^{2} \phi-t^{2}}\right)^{2} .
$$

\section{A.5 Proof of Policy Convergence}

Candidate $S$ wins the election with probability:

$$
1-P\left(\alpha_{N}, \alpha_{S}\right)=F_{\frac{\tilde{q}_{N}}{\tilde{q}_{S}}}\left(\frac{\alpha_{S}}{\lambda \alpha_{N}}\right)=\bar{F}\left(\frac{t}{\lambda}\right) .
$$

(A.22) implies that increasing the relative turnout level of the South (i.e., $t$ ) increases the probability of candidate $S$ being elected, while increasing relative size of the electorate in the North (that is, $\lambda$ ) decreases this probability. 
Consider first the case where firms in the North are subsidized, where the division of manufacturing activity adjusts until $\frac{\pi_{N}}{\pi_{S}}=\frac{1}{1+z_{N}}$. Solving this equilibrium condition for $v$, using the resulting expression in (2.18) and (2.19), substituting (2.18) and (2.19) into (3.20), then taking the first order condition of (A.22) to obtain:

$$
\frac{\partial(1-P)}{\partial z_{N}}=\frac{\partial \bar{F}}{\partial t} \frac{\partial t}{\partial V_{N}} \frac{\partial V_{N}}{\partial v} \frac{\partial v}{\partial z_{N}}+\frac{\partial \bar{F}}{\partial t} \frac{\partial t}{\partial V_{S}} \frac{\partial V_{S}}{\partial v} \frac{\partial v}{\partial z_{N}}=0
$$

which simplifies to:

$$
\frac{\partial(1-P)}{\partial z_{N}}=\frac{1}{V_{N}} \frac{\partial V_{N}}{\partial v}-\frac{1}{V_{S}} \frac{\partial V_{S}}{\partial v}=0 .
$$

Solving (A.24) for $z_{N}$ implies:

$$
1+z_{N}^{*}=\frac{\lambda^{2} \phi-t^{2}}{\lambda^{2}-t^{2} \phi}
$$

Consider then the case where production in the South is subsidized, where the division of firms adjusts until $\frac{\pi_{N}}{\pi_{S}}=1+z_{S}$. Solving this location condition for $v$, using the resulting expression in (2.18) and (2.19), substituting (2.18) and (2.19) into (3.20), then taking the first order condition of (A.22), and solving for $z_{S}$ yields:

$$
1+z_{S}^{*}=\frac{\lambda^{2}-t^{2} \phi}{\lambda^{2} \phi-t^{2}}
$$

Combining (A.25) and (A.26) gives (3.22):

$$
\theta^{*}=\frac{1+z_{S}^{*}}{1+z_{N}^{*}}=\left(\frac{\lambda^{2}-t^{2} \phi}{\lambda^{2} \phi-t^{2}}\right)^{2} .
$$

QED.

\section{A.6 Proof of $\theta^{*}>1$}

By (3.22) $\theta^{*}>1$ if $\left|\lambda^{2}-t^{2} \phi\right|>\left|\lambda^{2} \phi-t^{2}\right|$. Note that $\lambda^{2}-t^{2} \phi=\lambda-\omega \phi>0$, $\lambda^{2} \phi-t^{2}=\lambda \phi-\omega>0 \forall \phi>\frac{\omega}{\lambda}$, and $\lambda^{2} \phi-t^{2}<0 \forall \phi<\frac{\omega}{\lambda}$. This implies that:

$$
\left|\lambda^{2}-t^{2} \phi\right|=\lambda^{2}-t^{2} \phi
$$


and

$$
\left|\lambda^{2} \phi-t^{2}\right|=\left\{\begin{aligned}
\lambda^{2} \phi-t^{2} & \text { for } \phi>\frac{\omega}{\lambda} \\
-\left(\lambda^{2} \phi-t^{2}\right) & \text { for } \phi<\frac{\omega}{\lambda}
\end{aligned}\right.
$$

Consequently, $\theta^{*}>1 \forall \phi<\frac{\omega}{\lambda}$ if $\lambda^{2}-t^{2} \phi>-\left(\lambda^{2} \phi-t^{2}\right)$, and $\theta^{*}>1 \forall \phi>\frac{\omega}{\lambda}$ if $\lambda^{2}-t^{2} \phi>\lambda^{2} \phi-t^{2} . \lambda^{2}-t^{2} \phi>-\left(\lambda^{2} \phi-t^{2}\right) \Rightarrow \lambda>\omega \cdot \lambda^{2}-t^{2} \phi>\lambda^{2} \phi-t^{2} \Rightarrow$ $\lambda>-\omega$. Hence, $\theta^{*}>1$, which holds $\forall \phi \neq \frac{\omega}{\lambda}$. QED.

\section{A.7 Proof of $\frac{\partial \theta^{*}}{\partial \lambda} \leq 0$}

Equation (4.2) reproduced:

$$
\theta^{*}=f\left(Z_{j}\left(\lambda, t\left(V_{N}\left(\phi, v^{*}(\lambda, \phi)\right), V_{S}\left(\phi, v^{*}(\lambda, \phi)\right), \lambda\right), \phi\right)\right) .
$$

Taking the total derivative of (A.30) with respect to $\lambda$ gives:

$$
\begin{aligned}
& \frac{\partial \theta^{*}}{\partial \lambda}=\frac{\partial f}{\partial Z_{N}}\left(\frac{\partial Z_{N}}{\partial \lambda}+\frac{\partial Z_{N}}{\partial t} \frac{\partial t}{\partial \lambda}\right)+\frac{\partial f}{\partial Z_{S}}\left(\frac{\partial Z_{S}}{\partial \lambda}+\frac{\partial Z_{S}}{\partial t} \frac{\partial t}{\partial \lambda}\right) \\
& +\frac{\partial v^{*}}{\partial \lambda}\left(\frac{\partial f}{\partial Z_{N}} \frac{\partial Z_{N}}{\partial t}+\frac{\partial f}{\partial Z_{S}} \frac{\partial Z_{S}}{\partial t}\right)\left(\frac{\partial t}{\partial V_{N}} \frac{\partial V_{N}}{\partial v^{*}}+\frac{\partial t}{\partial V_{S}} \frac{\partial V_{S}}{\partial v^{*}}\right)
\end{aligned}
$$

where $\frac{\partial f}{\partial Z_{N}}<0, \frac{\partial Z_{N}}{\partial \lambda}=\frac{2 t^{2} \lambda\left(1-\phi^{2}\right)}{\left(\lambda^{2}-t^{2} \phi\right)^{2}} \geq 0, \frac{\partial Z_{N}}{\partial \lambda}+\frac{\partial Z_{N}}{\partial t} \frac{\partial t}{\partial \lambda}=\frac{t^{2} \lambda\left(1-\phi^{2}\right)}{\left(\lambda^{2}-t^{2} \phi\right)^{2}} \geq 0$, $\frac{\partial f}{\partial Z_{S}}>0, \frac{\partial Z_{S}}{\partial \lambda}=-\frac{2 t^{2} \lambda\left(1-\phi^{2}\right)}{\left(t^{2}-\lambda^{2} \phi\right)^{2}} \leq 0, \frac{\partial Z_{S}}{\partial \lambda}+\frac{\partial Z_{S}}{\partial t} \frac{\partial t}{\partial \lambda}=-\frac{t^{2} \lambda\left(1-\phi^{2}\right)}{\left(t^{2}-\lambda^{2} \phi\right)^{2}} \leq 0, \frac{\partial v^{*}}{\partial \lambda}=$ $-\frac{\left(\theta^{*}-\phi\right)\left(\theta^{*} \phi-1\right)\left(1-\phi^{2}\right)}{\left(\theta^{*}\left(1+\lambda \phi^{2}\right)-(1+\lambda) \phi\right)^{2}} \geq 0$ (by assumption), $\frac{\partial Z_{N}}{\partial t}=-\frac{2 t \lambda^{2}\left(1-\phi^{2}\right)}{\left(\lambda^{2}-t^{2} \phi\right)^{2}} \leq 0, \frac{\partial Z_{S}}{\partial t}=$ $\frac{2 t \lambda^{2}\left(1-\phi^{2}\right)}{\left(t^{2}-\lambda^{2} \phi\right)^{2}} \geq 0, \frac{\partial t}{\partial V_{N}}<0, \frac{\partial V_{N}}{\partial v^{*}}>0, \frac{\partial t}{\partial V_{S}}>0$, and $\frac{\partial V_{S}}{\partial v^{*}}<0$. Hence, $\frac{\partial \theta^{*}}{\partial \lambda} \leq 0$. QED.

\section{A.8 Determining the Sign of $\frac{\partial \theta^{*}}{\partial \phi}$}

Equation (4.2) reproduced:

$$
\theta^{*}=f\left(Z_{j}\left(\lambda, t\left(V_{N}\left(\phi, v^{*}(\lambda, \phi)\right), V_{S}\left(\phi, v^{*}(\lambda, \phi)\right), \lambda\right), \phi\right)\right) .
$$

Taking the total derivative of (A.32) with respect to $\phi$ to obtain: 


$$
\begin{aligned}
& \frac{\partial \theta^{*}}{\partial \phi}=\frac{\partial f}{\partial Z_{N}} \frac{\partial Z_{N}}{\partial \phi}+\frac{\partial f}{\partial Z_{S}} \frac{\partial Z_{S}}{\partial \phi} \\
& +\left(\frac{\partial f}{\partial Z_{N}} \frac{\partial Z_{N}}{\partial t}+\frac{\partial f}{\partial Z_{S}} \frac{\partial Z_{S}}{\partial t}\right)\left(\frac{\partial t}{\partial V_{N}}\left(\frac{\partial V_{N}}{\partial \phi}+\frac{\partial V_{N}}{\partial v^{*}} \frac{\partial v^{*}}{\partial \phi}\right)+\frac{\partial t}{\partial V_{S}}\left(\frac{\partial V_{S}}{\partial \phi}+\frac{\partial V_{S}}{\partial v^{*}} \frac{\partial v^{*}}{\partial \phi}\right)\right),
\end{aligned}
$$

where $\frac{\partial f}{\partial Z_{N}}<0, \frac{\partial Z_{N}}{\partial \phi}=\frac{\lambda^{4}-t^{4}}{\left(\lambda^{2}-t^{2} \phi\right)^{2}}>0, \frac{\partial f}{\partial Z_{S}}>0, \frac{\partial Z_{S}}{\partial \phi}=-\frac{\lambda^{4}-t^{4}}{\left(t^{2}-\lambda^{2} \phi\right)^{2}}<0$, $\frac{\partial Z_{N}}{\partial t}=-\frac{2 t \lambda^{2}\left(1-\phi^{2}\right)}{\left(\lambda^{2}-t^{2} \phi\right)^{2}} \leq 0, \frac{\partial Z_{S}}{\partial t}=\frac{2 t \lambda^{2}\left(1-\phi^{2}\right)}{\left(t^{2}-\lambda^{2} \phi\right)^{2}} \geq 0, \frac{\partial t}{\partial V_{N}}<0, \frac{\partial V_{N}}{\partial \phi}>0, \frac{\partial V_{N}}{\partial v^{*}}>0$, $\frac{\partial v^{*}}{\partial \phi}=\frac{(1+\lambda)\left(\lambda-2 \theta^{*} \phi(\lambda-1)-\phi^{2}+\theta^{* 2}\left(\lambda \phi^{2}-1\right)\right)}{\left(\theta^{*}\left(1+\lambda \phi^{2}\right)-(1+\lambda) \phi\right)^{2}}>0$ (by assumption), $\frac{\partial t}{\partial V_{S}}>0, \frac{\partial V_{S}}{\partial \phi}>0$ if $s_{N}>\frac{\partial s_{N}}{\partial \phi}(1-\phi)$, and $\frac{\partial V_{S}}{\partial v^{*}}<0$. Substituting (A.9) and (4.3) for the third term on the right-hand side of (A.33), $\frac{\partial \theta^{*}}{\partial \phi} \geq 0$ if:

$$
\frac{\partial f}{\partial Z_{N}} \frac{\partial Z_{N}}{\partial \phi}+\frac{\partial f}{\partial Z_{S}} \frac{\partial Z_{S}}{\partial \phi}+\frac{\partial \theta^{*}}{\partial t} \frac{\partial t}{\partial \phi} \geq 0
$$

where $\frac{\partial \theta^{*}}{\partial t} \frac{\partial t}{\partial \phi} \geq 0$ if the South is smaller than the threshold value, such that $\frac{\partial t}{\partial \phi}>0$. $\frac{\partial \theta^{*}}{\partial \phi} \leq 0$ if:

$$
\frac{\partial f}{\partial Z_{N}} \frac{\partial Z_{N}}{\partial \phi}+\frac{\partial f}{\partial Z_{S}} \frac{\partial Z_{S}}{\partial \phi}+\frac{\partial \theta^{*}}{\partial t} \frac{\partial t}{\partial \phi} \leq 0
$$

\section{A.9 Proof of Proposition 3}

Equation (4.4) reproduced:

$$
v^{*}=f\left(\theta^{*}, \lambda, \phi\right),
$$

where $\theta^{*}=f\left(Z_{j}\left(\lambda, t\left(V_{N}\left(\phi, v^{*}(\lambda, \phi)\right), V_{S}\left(\phi, v^{*}(\lambda, \phi)\right), \lambda\right), \phi\right)\right)$. Totally differentiating (A.36) with respect to $t$ yields:

$$
\frac{\partial v^{*}}{\partial t}=\frac{\partial f}{\partial \theta^{*}}\left(\frac{\partial \theta^{*}}{\partial Z_{N}} \frac{\partial Z_{N}}{\partial t}+\frac{\partial \theta^{*}}{\partial Z_{S}} \frac{\partial Z_{S}}{\partial t}\right),
$$

where $\frac{\partial f}{\partial \theta^{*}}=-\frac{\lambda\left(\phi^{2}-1\right)^{2}}{\left(\theta^{*}-\phi-\lambda \phi\left(1-\theta^{*} \phi\right)\right)^{2}}<0, \frac{\partial \theta^{*}}{\partial Z_{N}}<0, \frac{\partial Z_{N}}{\partial t}=-\frac{2 t \lambda^{2}\left(1-\phi^{2}\right)}{\left(\lambda^{2}-t^{2} \phi\right)^{2}} \leq 0$, $\frac{\partial \theta^{*}}{\partial Z_{S}}>0$, and $\frac{\partial Z_{S}}{\partial t}=\frac{2 t \lambda^{2}\left(1-\phi^{2}\right)}{\left(t^{2}-\lambda^{2} \phi\right)^{2}} \geq 0$. Consequently, $\frac{\partial v^{*}}{\partial t} \leq 0$. QED. 


\section{A.10 Proof of Proposition 4}

Equation (4.4) reproduced:

$$
v^{*}=f\left(\theta^{*}, \lambda, \phi\right),
$$

where $\theta^{*}=f\left(Z_{j}\left(\lambda, t\left(V_{N}\left(\phi, v^{*}(\lambda, \phi)\right), V_{S}\left(\phi, v^{*}(\lambda, \phi)\right), \lambda\right), \phi\right)\right)$. Taking the total derivative of (A.38) with respect to $\lambda$ and rearranging terms to obtain:

$$
\frac{\partial v^{*}}{\partial \lambda}=\frac{\frac{\partial f}{\partial \lambda}+\frac{\partial f}{\partial \theta^{*}}\left(\frac{\partial \theta^{*}}{\partial Z_{N}}\left(\frac{\partial Z_{N}}{\partial \lambda}+\frac{\partial Z_{N}}{\partial t} \frac{\partial t}{\partial \lambda}\right)+\frac{\partial \theta^{*}}{\partial Z_{S}}\left(\frac{\partial Z_{S}}{\partial \lambda}+\frac{\partial Z_{S}}{\partial t} \frac{\partial t}{\partial \lambda}\right)\right)}{1-\frac{\partial f}{\partial \theta^{*}}\left(\frac{\partial \theta^{*}}{\partial Z_{N}} \frac{\partial Z_{N}}{\partial t}+\frac{\partial \theta^{*}}{\partial Z_{S}} \frac{\partial Z_{S}}{\partial t}\right)\left(\frac{\partial t}{\partial V_{N}} \frac{\partial V_{N}}{\partial v^{*}}+\frac{\partial t}{\partial V_{S}} \frac{\partial V_{S}}{\partial v^{*}}\right)}
$$

where $\frac{\partial f}{\partial \lambda}=-\frac{\left(\theta^{*}-\phi\right)\left(\theta^{*} \phi-1\right)\left(1-\phi^{2}\right)}{\left(\theta^{*}\left(1+\lambda \phi^{2}\right)-(1+\lambda) \phi\right)^{2}}>0$ is assumed, $\frac{\partial f}{\partial \theta^{*}}=-\frac{\lambda\left(\phi^{2}-1\right)^{2}}{\left(\theta^{*}-\phi-\lambda \phi\left(1-\theta^{*} \phi\right)\right)^{2}}<0$, $\frac{\partial \theta^{*}}{\partial Z_{N}}<0, \frac{\partial Z_{N}}{\partial \lambda}+\frac{\partial Z_{N}}{\partial t} \frac{\partial t}{\partial \lambda}=\frac{t^{2} \lambda\left(1-\phi^{2}\right)}{\left(\lambda^{2}-t^{2} \phi\right)^{2}} \geq 0, \frac{\partial \theta^{*}}{\partial Z_{S}}>0, \frac{\partial Z_{S}}{\partial \lambda}+\frac{\partial Z_{S}}{\partial t} \frac{\partial t}{\partial \lambda}=-\frac{t^{2} \lambda\left(1-\phi^{2}\right)}{\left(t^{2}-\lambda^{2} \phi\right)^{2}} \leq$ $0, \frac{\partial Z_{N}}{\partial \lambda}=\frac{2 t^{2} \lambda\left(1-\phi^{2}\right)}{\left(\lambda^{2}-t^{2} \phi\right)^{2}} \geq 0, \frac{\partial Z_{N}}{\partial t}=-\frac{2 t \lambda^{2}\left(1-\phi^{2}\right)}{\left(\lambda^{2}-t^{2} \phi\right)^{2}} \leq 0, \frac{\partial Z_{S}}{\partial \lambda}=-\frac{2 t^{2} \lambda\left(1-\phi^{2}\right)}{\left(t^{2}-\lambda^{2} \phi\right)^{2}} \leq 0$, $\frac{\partial Z_{S}}{\partial t}=\frac{2 t \lambda^{2}\left(1-\phi^{2}\right)}{\left(t^{2}-\lambda^{2} \phi\right)^{2}} \geq 0, \frac{\partial t}{\partial V_{N}}<0, \frac{\partial V_{N}}{\partial v^{*}}>0, \frac{\partial t}{\partial V_{S}}>0$, and $\frac{\partial V_{S}}{\partial v^{*}}<0$. Hence, $\frac{\partial v^{*}}{\partial \lambda}>\frac{\partial f}{\partial \lambda}>0$ if $\zeta \equiv \frac{\partial f}{\partial \theta^{*}}\left(\frac{\partial \theta^{*}}{\partial Z_{N}} \frac{\partial Z_{N}}{\partial t}+\frac{\partial \theta^{*}}{\partial Z_{S}} \frac{\partial Z_{S}}{\partial t}\right)\left(\frac{\partial t}{\partial V_{N}} \frac{\partial V_{N}}{\partial v^{*}}+\frac{\partial t}{\partial V_{S}} \frac{\partial V_{S}}{\partial v^{*}}\right)<1$, and $\frac{\partial v^{*}}{\partial \lambda}<0<\frac{\partial f}{\partial \lambda}$ if $\zeta \equiv \frac{\partial f}{\partial \theta^{*}}\left(\frac{\partial \theta^{*}}{\partial Z_{N}} \frac{\partial Z_{N}}{\partial t}+\frac{\partial \theta^{*}}{\partial Z_{S}} \frac{\partial Z_{S}}{\partial t}\right)\left(\frac{\partial t}{\partial V_{N}} \frac{\partial V_{N}}{\partial v^{*}}+\frac{\partial t}{\partial V_{S}} \frac{\partial V_{S}}{\partial v^{*}}\right)>1$. QED.

\section{A.11 Proof of Proposition 5}

Equation (4.4) reproduced:

$$
v^{*}=f\left(\theta^{*}, \lambda, \phi\right),
$$

where $\theta^{*}=f\left(Z_{j}\left(\lambda, t\left(V_{N}\left(\phi, v^{*}(\lambda, \phi)\right), V_{S}\left(\phi, v^{*}(\lambda, \phi)\right), \lambda\right), \phi\right)\right)$. Totally differentiating (A.40) with respect to $\phi$ and rearranging terms yields:

$$
\frac{\partial v^{*}}{\partial \phi}=\frac{\frac{\partial f}{\partial \phi}+\frac{\partial f}{\partial \theta^{*}}\left(\frac{\partial \theta^{*}}{\partial Z_{N}} \frac{\partial Z_{N}}{\partial \phi}+\frac{\partial \theta^{*}}{\partial Z_{S}} \frac{\partial Z_{S}}{\partial \phi}+\left(\frac{\partial \theta^{*}}{\partial Z_{N}} \frac{\partial Z_{N}}{\partial t}+\frac{\partial \theta^{*}}{\partial Z_{S}} \frac{\partial Z_{S}}{\partial t}\right)\left(\frac{\partial t}{\partial V_{N}} \frac{\partial V_{N}}{\partial \phi}+\frac{\partial t}{\partial V_{S}} \frac{\partial V_{S}}{\partial \phi}\right)\right)}{1-\frac{\partial f}{\partial \theta^{*}}\left(\frac{\partial \theta^{*}}{\partial Z_{N}} \frac{\partial Z_{N}}{\partial t}+\frac{\partial \theta^{*}}{\partial Z_{S}} \frac{\partial Z_{S}}{\partial t}\right)\left(\frac{\partial t}{\partial V_{N}} \frac{\partial V_{N}}{\partial v^{*}}+\frac{\partial t}{\partial V_{S}} \frac{\partial V_{S}}{\partial v^{*}}\right)}
$$

where $\frac{\partial f}{\partial \phi}=\frac{(1+\lambda)\left(\lambda-2 \theta^{*} \phi(\lambda-1)-\phi^{2}+\theta^{* 2}\left(\lambda \phi^{2}-1\right)\right)}{\left(\theta^{*}\left(1+\lambda \phi^{2}\right)-(1+\lambda) \phi\right)^{2}}>0$ (by assumption), $\frac{\partial f}{\partial \theta^{*}}=-\frac{\lambda\left(\phi^{2}-1\right)^{2}}{\left(\theta^{*}-\phi-\lambda \phi\left(1-\theta^{*} \phi\right)\right)^{2}}<$ $0, \frac{\partial \theta^{*}}{\partial Z_{N}}<0, \frac{\partial Z_{N}}{\partial \phi}=\frac{\lambda^{4}-t^{4}}{\left(\lambda^{2}-t^{2} \phi\right)^{2}}>0, \frac{\partial \theta^{*}}{\partial Z_{S}}>0, \frac{\partial Z_{S}}{\partial \phi}=-\frac{\lambda^{4}-t^{4}}{\left(t^{2}-\lambda^{2} \phi\right)^{2}}<0, \frac{\partial Z_{N}}{\partial t}=$ 
$-\frac{2 t \lambda^{2}\left(1-\phi^{2}\right)}{\left(\lambda^{2}-t^{2} \phi\right)^{2}} \leq 0, \frac{\partial Z_{S}}{\partial t}=\frac{2 t \lambda^{2}\left(1-\phi^{2}\right)}{\left(t^{2}-\lambda^{2} \phi\right)^{2}} \geq 0, \frac{\partial t}{\partial V_{N}}<0, \frac{\partial V_{N}}{\partial \phi}>0, \frac{\partial t}{\partial V_{S}}>0, \frac{\partial V_{S}}{\partial \phi}>0$, $\frac{\partial V_{N}}{\partial v^{*}}>0$, and $\frac{\partial V_{S}}{\partial v^{*}}<0$. Thus,

$\frac{\partial f}{\partial \theta^{*}}\left(\frac{\partial \theta^{*}}{\partial Z_{N}} \frac{\partial Z_{N}}{\partial \phi}+\frac{\partial \theta^{*}}{\partial Z_{S}} \frac{\partial Z_{S}}{\partial \phi}+\left(\frac{\partial \theta^{*}}{\partial Z_{N}} \frac{\partial Z_{N}}{\partial t}+\frac{\partial \theta^{*}}{\partial Z_{S}} \frac{\partial Z_{S}}{\partial t}\right)\left(\frac{\partial t}{\partial V_{N}} \frac{\partial V_{N}}{\partial \phi}+\frac{\partial t}{\partial V_{S}} \frac{\partial V_{S}}{\partial \phi}\right)\right)>0$ if $\frac{\partial t}{\partial V_{N}} \frac{\partial V_{N}}{\partial \phi}+\frac{\partial t}{\partial V_{S}} \frac{\partial V_{S}}{\partial \phi} \leq 0 \Rightarrow \frac{\partial V_{N}}{\partial \phi} / \frac{\partial V_{S}}{\partial \phi} \geq V_{N} / V_{S}$, since $-\frac{\partial t}{\partial V_{N}} / \frac{\partial t}{\partial V_{S}}=V_{S} / V_{N}$. Accordingly, $\frac{\partial v^{*}}{\partial \phi}>\frac{\partial f}{\partial \phi}>0$ if $\zeta \equiv \frac{\partial f}{\partial \theta^{*}}\left(\frac{\partial \theta^{*}}{\partial Z_{N}} \frac{\partial Z_{N}}{\partial t}+\frac{\partial \theta^{*}}{\partial Z_{S}} \frac{\partial Z_{S}}{\partial t}\right)\left(\frac{\partial t}{\partial V_{N}} \frac{\partial V_{N}}{\partial v^{*}}+\frac{\partial t}{\partial V_{S}} \frac{\partial V_{S}}{\partial v^{*}}\right)<$ 1 , and $\frac{\partial v^{*}}{\partial \phi}<0<\frac{\partial f}{\partial \phi}$ if $\zeta \equiv \frac{\partial f}{\partial \theta^{*}}\left(\frac{\partial \theta^{*}}{\partial Z_{N}} \frac{\partial Z_{N}}{\partial t}+\frac{\partial \theta^{*}}{\partial Z_{S}} \frac{\partial Z_{S}}{\partial t}\right)\left(\frac{\partial t}{\partial V_{N}} \frac{\partial V_{N}}{\partial v^{*}}+\frac{\partial t}{\partial V_{S}} \frac{\partial V_{S}}{\partial v^{*}}\right)>1$. QED. 